Type of the Paper (Article, Review, Communication, etc.)

\title{
Differential impacts of climatic and land use changes on habitat suitability and protected area adequacy across the Asian elephant's range
}

\author{
Wei Yang 1, 2,3, Yuanxu Ma 1,2*, Linhai Jing 1,2, Siyuan Wang 4, Zhongchang Sun 1,2, Yunwei Tang 1,2, Hui Li 1,2 \\ 1 Aerospace Information Research Institute, Chinese Academy of Sciences, Beijing 100094, China; \\ yangwei191@mails.ucas.ac.cn (W.Y.); mayuanxu@pku.org.cn (Y.M.); jinglh@aircas.ac.cn (L.J.); \\ sunzc@aircas.ac.cn (Z.S.); tangyw@aircas.ac.cn (Y.T.); lihui@radi.ac.cn (H.L.) \\ 2 International Research Center of Big Data for Sustainable Development Goals, Beijing 100094, China \\ 3 University of Chinese Academy of Sciences, Beijing 100049, China \\ 4 Research Center for Eco-Environmental Sciences, State Key Laboratory of Urban and Regional Ecology, \\ Chinese Academy of Sciences, Beijing 100085, China; wangsy@rcees.ac.cn \\ * Correspondence: mayuanxu@pku.org.cn
}

\begin{abstract}
The reduction of biodiversity loss is one of the targets of the 2030 Agenda for Sustainable Development. The protection of endangered species is critical for conserving global biodiversity. Asian elephants, as one of the last few mega-herbivores on Earth, are currently threatened by climate changes and anthropogenic modifications. The modelling of their living habitats is of top priority to the conservation of Asian elephant. In this study, we used the maximum entropy model (MaxEnt) to identify the current and potential future habitats of Asian elephants in South and Southeast Asia. We performed analyses for future projections with 17 scenarios by using the present results as baseline. To optimise the modelling results, we delineated the core habitats by using the Core Mapper Tool and compared them with existing protected areas (PAs) through gap analysis. The results showed that the current total area of core habitats is $491,455 \mathrm{~km}^{2}$ in size and will be reduced to 332,544 $\mathrm{km}^{2}$ by 2090 under SSP585 (the shared socioeconomic pathway). The projection analysis under differential scenarios suggested that most of the core habitats in the current protected areas would remain stable and suitable for elephants in the future. However, the remaining 75.17\% of the core habitats lay outside the current PAs, and finally we mapped approximately $219,545 \mathrm{~km}^{2}$ of suitable habitats as priority protected areas in the future. Although our model did not perform well in some regions, our analyses and findings still could provide useful references to the planning of protected areas and conservation of Asian elephant.
\end{abstract}

Keywords: Asian elephant; MaxEnt; habitat suitability; protected area; climate change; human footprint

\section{Introduction}

The concept of sustainable development is based on the three human-nature interrelated dimensions: economy, society and environment [1]. The importance of environment has received increasing concerns. The Millennium Development Goals incorporated the Convention on Biological Diversity (CBD) target were initiated to achieve a significant reduction of the current rate of biodiversity loss. And among the 17 goals in the 2030 Agenda for Sustainable Development, biodiversity was also included in SDG 14 (Life below water) and SDG 15 (Life on land). The loss of biodiversity will alter the ecosystem functions and their ability to the provision of goods and services [2]. The conservation of biodiversity may contribute to the implementation of hunger eradication and food provision.

Asian elephants are one of the few mega-herbivores on Earth. Asian elephants were historically widespread, once ranging from the Euphrates and Tigris rivers in the west to 
the Yangtze River in the east [3]. However, 85\% of Asian elephants have been extirpated, and currently, only a few populations live in fragmented and isolated patches in South and Southeast Asia. In 2018, the estimated population size of wild Asian elephants ranged from 48,323 to 51,680 [4]. The International Union for Conservation of Nature (IUCN) included Asian elephants on the endangered species list. Although many conservation measures have been taken to maintain and improve their living environment, Asian elephants still face severe threats from climate change and human activities. The conservation of Asian elephants is an essential component of biodiversity conservation and is a task that should be prioritized urgently [5].

In order to protect the habitats of Asian elephants, many investigations have been conducted [6-17]. Early studies focused on the analyses of habitat status or suitability by using field survey data [9,11,16-18], while recent studies began to model habitat suitability or change under climate change and human disturbance [6,14,15,19-21]. South and Southeast Asia are the most vulnerable regions to climate change [22,23]. It was predicted that an increase in temperature would be spatially homogenous, while an increase in precipitation would show great spatial variability $[23,24]$. Climate change has been one of the most important drivers for the historical shift in the range of distribution of Asian elephants [3]. A number of studies showed that the climate change exerts substantial influence on the variation of the habitat of Asian elephants [6,20,25]. However, human pressure that causes this elephant's habitat to change is increasing[7,13,26]. Humanelephant conflicts have been reported more frequently in recent years and have caused many casualties $[27,28]$. Human impacts on elephants have been caused by various land use activities, including urban and agricultural land expansion and the clearance of forests. These activities can lead to the loss and fragmentation of the habitat of Asian elephants, which would affect biodiversity and ecosystem functioning [29,30]. Human activities have resulted in increased fragmentation in habitat for Asian elephants, which has significantly reduced elephant migration and habitat connectivity [31].

Species distribution models (SDMs) are important tools in species habitat simulation because they combine specific species with niche factors [32-34]. Various kinds of SDMs have been used in modeling of the habitat of Asian elephants [10,21,25,30]. The most commonly used SDMs include generalized linear models (GLM), generalized additive models (GAMs), classification tree analysis (CTA), artificial neural networks (ANN), random forest (RF), generalized boosting models (GBMs), multiple adaptive regression splines (MARS), flexible discriminant analysis (FDA), and maximum entropy (MaxEnt) [25,35-38]. Of all the SDMs, MaxEnt is the among the mostly commonly used models with regard to habitat simulation and prediction [6,36,39-41]. The advantage of this model is that it can allow us to infer species distributions and environmental tolerances from occurrence data and fit models with arbitrary complexity [41].

At present, most of the previous studies in this field focused on specific regions $[11,25,30,42,43]$; only a few carried out analytic experiments over the entire Asian elephant habitat area [44]. The establishment of protected areas (PAs) was expected to maintain biodiversity [45] and protect endangered species from human intervention [46]. Although several PAs for Asian elephants have been established in South and Southeast Asia, their effectiveness for conservation has not been comprehensively evaluated. Consequently, the aim of this study was to use the maximum entropy model (MaxEnt) to identify potential future habitats for Asian elephants in South and Southeast Asia and project changes in the future due to climate change and human activities. Our specific objectives were to (1) assess the contribution of various environmental factors to the habitat suitability of Asian elephants; (2) map the core habitat distribution of Asian elephants and their spatial transformation in the future; (3) assess the impact of human activities on the core habitats of Asian elephants; and (4) appraise the conservation efficiency of existing PAs for Asian elephants.

\section{Materials and Methods}




\subsection{Study Area}

The area that was studied is located in South and Southeast Asia $\left(6^{\circ} \mathrm{S}-35^{\circ} \mathrm{N}, 68^{\circ}\right.$ $119^{\circ} \mathrm{E}$ ), including 13 countries and regions (Bangladesh, Bhutan, Cambodia, India, Indonesia, Laos, Malaysia, Myanmar, Nepal, Sri Lanka, Thailand, Vietnam, and Yunnan of China) that are associated with Asian elephant activity [47]. The study area covered a total area of 7,165,810 $\mathrm{km}^{2}$ (Figure 1).

This area has substantial topographic relief, with the elevation ranging from sea level to $8000 \mathrm{~m}$ above sea level in the Himalayas. The climate is also spatially different, varying from extremely arid regions to extremely humid regions, from extremely hot to extremely cold, and from drought-prone areas to flood-prone areas [48]. A large proportion of annual rainwater in the region comes from summer monsoons [49]. The entire region is strongly affected by southwest and northeast monsoons [50]. The land cover types in the study area are complex, with forest and cropland being the most predominant.

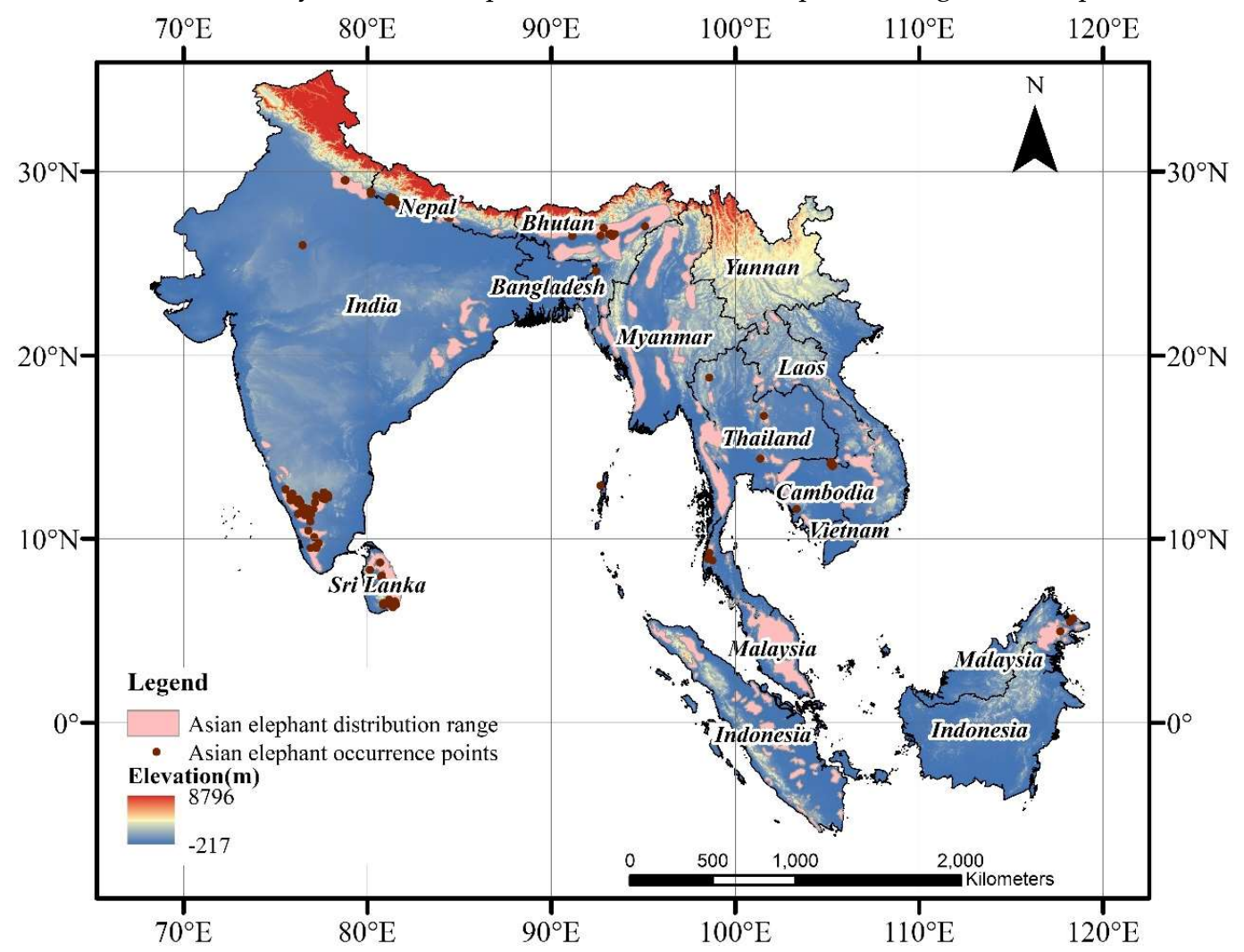

Figure 1. Geographical location of the study area and the distribution range of Asian elephants mapped by IUCN.

\subsection{Elephant Occurrence Data}

The recorded Asian elephant occurrence events were compiled from the Global Biodiversity Information Facility (GBIF) [51] and the published literature [42]. We only chose the events recorded after 1990 whose uncertainty distance was less than $1 \mathrm{~km}$. To minimize the sampling bias that could result in model overfitting, we only selected locations which were a minimum of $1 \mathrm{~km}$ apart from each other, and we also performed a manual check to ensure that there was only one point in each pixel [52]. The final records were 178 occurrence points.

\subsection{Model Variables}

\subsubsection{Topography}

We used SRTM DEM to calculate topographic slope, land surface roughness, the terrain ruggedness index, the topographic position index, and the topographic wetness 
index [53]. We also used hydrographic data generated from Shuttle Elevation Derivatives at multiple scales (HydroSHEDS, [54]) to calculate the distance from a certain point to the adjacent surface water.

\subsubsection{Vegetation variables}

The Terra and Aqua Moderate-Resolution Imaging Spectroradiometer (MODIS) provides many vegetation products. We used the Normalized Difference Vegetation Index (NDVI), the Leaf Area Index (LAI), and Vegetation Continuous Fields (VCF) products [55-57] to represent the vegetation variables. All the variables were averaged across 2000-2020. As a forest vertical structure is a significant predictor of aboveground live biomass, primary productivity, and biodiversity, we obtained the canopy height developed by combining radar and Light Detecting and Ranging (LiDAR) remote sensing from the Jet Propulsion Laboratory of the California Institute of Technology[58]. We used the Land Use and Land Cover (LULC) product derived from the European Space Agency (ESA) Climate Change Initiative (CCI) [59] to reclassify the vegetation into 11 categories (Table 1). This product is combined with the human land use type in Section 2.3.3 as the LULC variable.

Table 1. Reclassification of ESA CCI land cover product.

\begin{tabular}{ccc}
\hline Class number & ESA CCI LC class number & Description \\
\hline 0 & 210 & Water body \\
1 & $10-20$ & Cropland \\
2 & $30-40$ & Mosaic of cropland and natural vegetation \\
3 & 190 & Urban \\
4 & 50 & Evergreen broad-leaved forest \\
5 & $60-62$ & Deciduous broad-leaved forest \\
6 & $70-72$ & Evergreen needle-leaved forest \\
7 & $80-82$ & Deciduous needle-leaved forest \\
8 & 90 & Mixed forests \\
9 & $100-110$ & Mosaic of tree, shrub, and herbaceous \\
10 & $120-122$ & Shrubland \\
11 & 130 & Grass \\
12 & 140 & Lichens and mosses \\
13 & $150-153$ & Sparse vegetation \\
14 & $160-180$ & Flooded trees and shrubs \\
15 & $200-202$ & Bare \\
16 & 220 & Snow and ice \\
\hline
\end{tabular}

\subsubsection{Anthropogenic variables}

Land use is a direct transformation of nature by humans $[60,61]$ and has a substantial impact on elephant habitats [30]. We focused on urban area and cropland because these land use types have significant pressure on the environment. The expansion of cropland and urban areas has led to a certain degree of loss, degradation, and fragmentation in the natural and semi-natural habitats of elephants and has also increased human-elephant conflict [5,62-64]. The urban and cropland covers were extracted from the ESA CCI land cover product (Table 1). Urban expansion has affected different species due to land use change and its consequent effects (e.g., urban heat island, night-time lights, and impervious surface construction, etc.) [65-67]. Here, we used the distance to urban areas as the measurement to determine urban effects on elephant habitats. We also used the WorldPop database to calculate the population density [68]. Roads and railways can break habitat connectivity and prevent elephant migration within their habitat range. We calculated the distance from Asian elephants' habitats to roads and railways based on the 
OpenStreetMap [69] and Global Roads Inventory Project (GRIP) [70] to map road interruption.

\subsubsection{Climatic variables}

We collected climate data in the current period from WorldClim with 30 arc second resolution [71]. We used 19 bioclimatic variables of the WorldClim dataset in our study, and we also derived 15 other bioclimatic variables calculated from WorldClim data by ENVIREM [72]. The annual AET was obtained from CGIAR-CSI [73]. All the climatic variables are shown in Table 2.

Table 2. All 35 climate variables.

\begin{tabular}{|c|c|c|c|}
\hline Source & Variable & Source & Variable \\
\hline \multirow{19}{*}{ WorldClim } & Annual Mean Temperature & \multirow{15}{*}{ ENVIREM } & Aridity Index \\
\hline & Mean Diurnal Range & & Climatic Moisture Index \\
\hline & Isothermality & & Continentality \\
\hline & Temperature Seasonality & & Pluviothermic Quotient \\
\hline & Max Temperature of Warmest Month & & Growing Degree Days $\left(0^{\circ} \mathrm{C}\right)$ \\
\hline & Min Temperature of Coldest Month & & Growing Degree Days $\left(5^{\circ} \mathrm{C}\right)$ \\
\hline & Temperature Annual Range & & Max Temperature of Coldest Month \\
\hline & Mean Temperature of Wettest Quarter & & Min Temperature of Warmest Month \\
\hline & Mean Temperature of Driest Quarter & & Count of Month Greater than $10^{\circ} \mathrm{C}$ \\
\hline & Mean Temperature of Warmest Quarter & & PET of Coldest Quarter \\
\hline & Mean Temperature of Coldest Quarter & & PET of Driest Quarter \\
\hline & Annual Precipitation & & PET Seasonality \\
\hline & Precipitation of Wettest Month & & PET of Warmest Quarter \\
\hline & Precipitation of Driest Month & & PET of Wettest Quarter \\
\hline & Precipitation Seasonality & & Annual PET \\
\hline & Precipitation of Wettest Quarter & \multirow[t]{4}{*}{ CGIAR-CSI } & \multirow[t]{4}{*}{ Annual AET } \\
\hline & Precipitation of Driest Quarter & & \\
\hline & Precipitation of Warmest Quarter & & \\
\hline & Precipitation of Coldest Quarter & & \\
\hline
\end{tabular}

\subsubsection{Variable selection}

In total, we obtained 52 input variables, including 7 topographic, 5 vegetation, 5 anthropogenic, and 35 climatic variables. In order to avoid overfitting, highly correlated variables were removed. We calculated Pearson's correlation coefficient between all variables and removed variables with $|\mathrm{r}|>0.8$ (Figure 2) [52,74]. The remaining 22 variables were input into the MaxEnt model as predictor variables; however, the variables with contributions less than 1\% were neglected [75]. Finally, 15 independent variables were used to model the suitable habitat area for Asian elephants (Figure 2). 


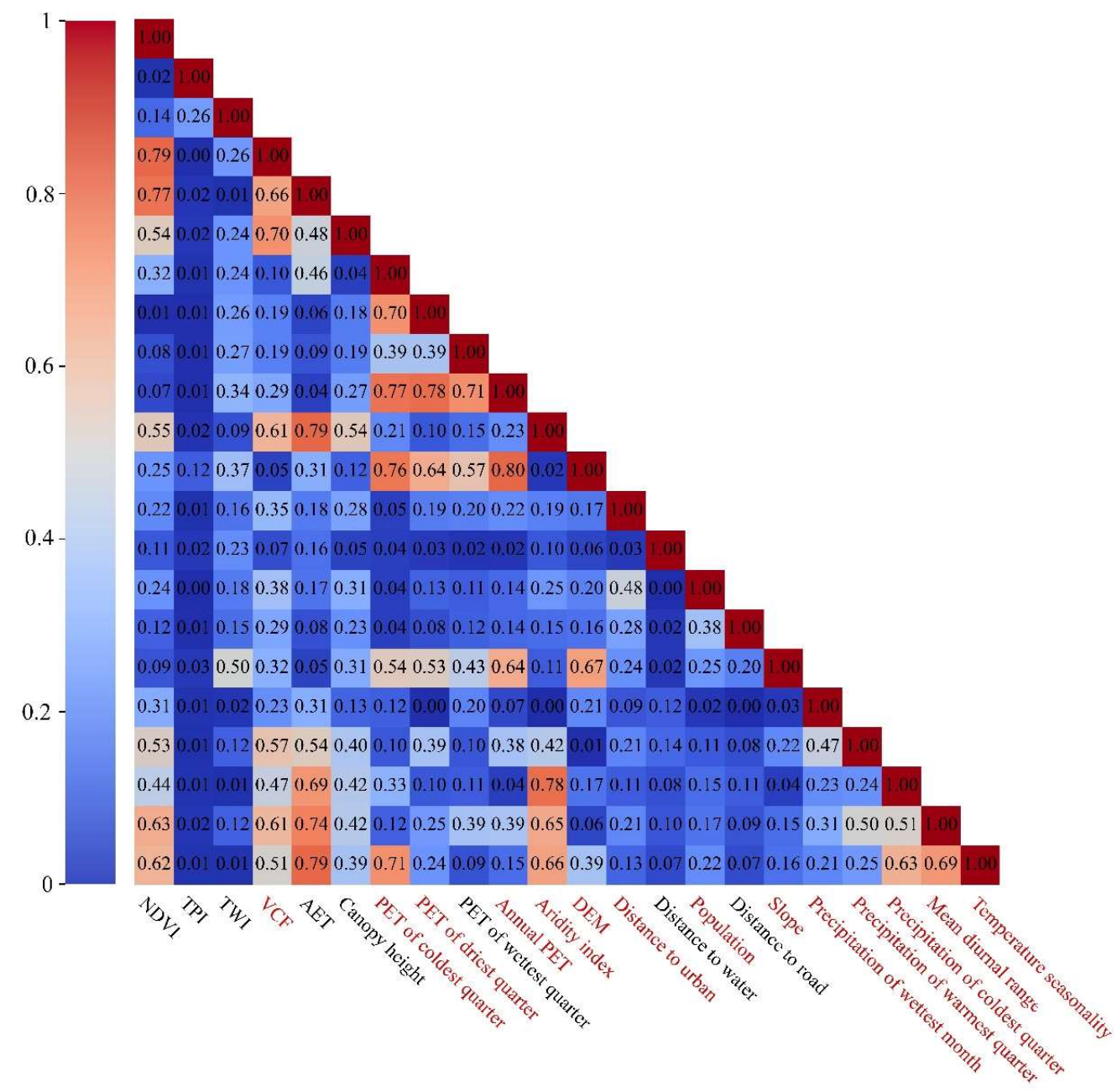

Figure 2. Correlation plot of 22 independent variables. The variables marked with red color were finally selected.

\subsection{Species Distribution Modeling and Evaluation}

We used 178 elephant occurrence events as input of the MaxEnt model [76], and all environment variables are resampled to $1 \mathrm{~km}$. In this study, we performed four-fold crossvalidation, with all analyses based on the average [77] and all other parameters as default. A jackknife test was used to determine the contribution of each variable to elephant distribution. The performance of the MaxEnt model was evaluated by using the AUC (Area Under the ROC-receiver operating curve) [78]. An AUC value of 0.5-0.7 indicates poor performance, 0.7-0.9 indicates moderate performance, and a value greater than 0.9 indicates high performance [79]. The determination of the potential habitat was based on the 10 percentiles of the training presence, which is a common threshold used in species distribution modeling [52].

\subsection{Projecting Future Potential Habitat}

In order to assess the impact of future climate change and human disturbance, we used the MaxEnt model to project potential habitats of elephants during four future periods (i.e., 2030, 2050, 2070, and 2090) under the four most representative scenarios: (1) SSP126 (SSP1) is a sustainable pathway and uses green roads; (2) SSP245 (SSP2) is a middle pathway between SSP126 and SSP370; (3) SSP370 (SSP3) is a regional rivalry pathway contrary to global cooperation; (4) SSP585 (SSP5) is a fossil-fueled development pathway in which the global economy grows rapidly, but people face severe mitigation challenges [80]. We obtained future climatic variables from Centre National de Recherches 
Météorologiques Coupled Global Climate Model, version 6 (CNRM-CM6) [81], which is under the latest Coupled Model Inter-Comparison Project (CMIP6) framework [82] (www.worldclim.org). We used global projections data regarding future urban land expansion [80] to simulate the change of human disturbance. These data projected the future (2020 to 2100) urban land expansion at $1 \mathrm{~km}$ resolution under SSPs (SSP1, SSP2, SSP3, SSP4, and SSP5 based on ESA CCI land cover in 2015. Using this data, we calculated the distance of the given place to urban areas and the land use type (only the category of urban) dynamic. The remaining variables remained static because they had no projection data.

\subsection{Assessing Disturbance and Protection in the Core Habitat}

\subsubsection{Core habitat identification}

As the MaxEnt model only predicted the suitability of individual pixels without accounting for the minimum range of species migration, we identified core habitats as being contiguous, highly suitable habitat areas. We used the Core Mapper tool from the Gnarly Landscape Utilities to identify core habitats throughout the study area [83]. We identified highly suitable habitat patches in the study area by using a moving window with a $9.4 \mathrm{~km}$ radius [23]. In addition, cells within a certain effective distance were included in the targeted core habitats. First, we defined a resistance surface (i.e., resistance $=1 /$ habitat suitability). Then, the resistance value was multiplied with the minimum distance of this cell from the core area to obtain an effective distance. The cells within an effective distance of $60 \mathrm{~km}$ [84] were included in the core habitat area [25]. This could connect small nearby patches within a reachable distance, resulting in fewer but larger core habitats.

\subsubsection{Human footprint in core habitats}

To evaluate the human pressure on the core habitat, we calculated the degree of human footprint proposed by Sanderson and Venter, which included 8 types of human activity stressors $[85,86]$. In addition, we used reservoirs as another input layer. These pressures were weighted following Venter, Sanderson, and Theobald [85-87]. All of this information can be found in Table 3.

Table 3. Pressure score of all 9 stressors.

\begin{tabular}{|c|c|c|c|c|}
\hline Pressure & Scores & Description & Time & Source \\
\hline Build & 0,10 & All builds set with a score of 10 & $2000-2018$ & ESA CCI LC[59] \\
\hline Cropland & 0,7 & All croplands set with a score of 7 & 2000-2018 & ESA CCI LC [59] \\
\hline Pasture $^{*}$ & $0-4$ & $\begin{array}{l}\text { All pastures set with a score ranged } 0-4 \text { based on } \\
\text { intensity }\end{array}$ & 2000 & Farming the planet[88] \\
\hline Reservoir & 0,7 & All reservoirs set with a score of 7 & 2000-2018 & GRanD[89] \\
\hline Population & $0-10$ & Pressure score $=3.333 \times \log ($ population density +1$)$ & $2000-2018$ & Worldpop[68] \\
\hline Night light & $0-10$ & Equal quintile bins & $2000-2018$ & VIIRS-Like[90] \\
\hline Road $^{*}$ & 0,8 Direct & $\begin{array}{l}\text { 500m either side of roads given a direct pressure score } \\
\qquad \text { of } 8(4.4,1.5)\end{array}$ & 2018 & GRIP[70] \\
\hline & $0-4$ Indirect & $\begin{array}{l}\text { Starting } 500 \mathrm{~m} \text { out from road, pressure score of } 4(2.2, \\
0.75) \text { exponentially decaying out to } 15 \mathrm{~km}\end{array}$ & & \\
\hline Railway* $^{*}$ & 0,8 & $\begin{array}{l}500 \mathrm{~m} \text { either side of railways given a direct pressure } \\
\text { score of } 8\end{array}$ & 2018 & openstreetmap[69] \\
\hline Waterway* & $0-4$ & Pressure score of 4 exponentially decaying out to $15 \mathrm{~km}$ & 2018 & openstreetmap[69] \\
\hline
\end{tabular}


before 2000. In addition, we validated our human footprint results by using the same validation set as Venter's, and the statistical parameters for model validation (RMSE, R², and Kappa) showed that our products were improved.

\subsubsection{Gap analysis}

Gap analysis is a popular method for use in evaluating the effectiveness of PAs [52]. In order to assess the effectiveness of existing PAs, we compared the core habitats with existing PAs [91]. Then, we extracted core habitats inside and outside the PAs and calculated their area and proportion to evaluate the conservation efficiency of the existing PAs.

The working procedure of all our analyses can be found in Figure 3. We applied Maxent version 3.4.3 to perform habitat suitability modeling [92]. We finished all the analyses by using the packages usdm, seaborn, and matplotlib in R and Python. Spatial processing was completed in ArcMap 10.2.

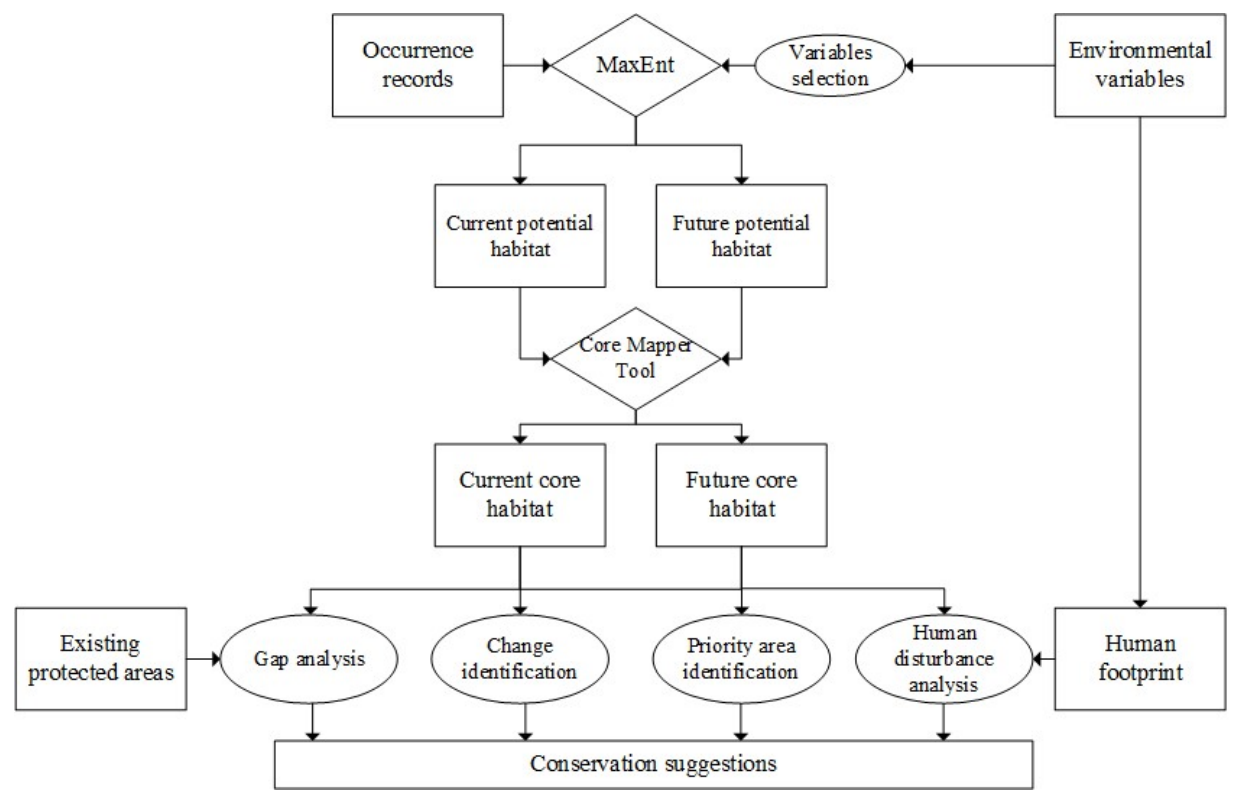

Figure 3. Flowchart showing the method of habitat suitability analysis for Asian elephants.

\section{Results}

\subsection{Model Performance}

The modeling accuracy for the current and future distribution of Asian elephants in our study area was reliable. The $A U C_{\text {train }}$ and $A U C_{\text {test }}$ were found to be 0.971 and 0.946 , respectively, indicating high performance (AUC score $>0.9$ ). This showed that the MaxEnt model performed well in predicting the suitable habitat of elephants based on currently available data.

Among 15 environmental variables in the model simulation, the 5 variables with the highest contributions included precipitation of coldest quarter, population, aridity index, LULC, and distance to urban area, which accounted for $71.6 \%$ of the modeling results (Table 4). The response curves for these five variables showed that elephants prefer forest and mixed areas with trees and shrubs, and herbaceous, relatively dry environments with high PET, free from high human impact (Figure 4).

Table 4. Variables contribution for modeling.

\begin{tabular}{ccc}
\hline Variable & Percent Contribution & Type \\
\hline Precipitation of coldest quarter* & 25.1 & Climatic \\
\hline
\end{tabular}




\begin{tabular}{ccc}
\hline Population & 22.9 & Anthropogenic \\
Aridity index* & 13.4 & Climatic \\
LULC $^{*}$ & 5.4 & Anthropogenic \\
Distance to urban area* & 4.9 & Anthropogenic \\
DEM & 4 & Topographical \\
Slope & 4 & Topographical \\
VCF & 3.7 & Vegetation \\
PET of coldest quarter* & 3.7 & Climatic \\
Temperature seasonality* & 3.5 & Climatic \\
Precipitation of wettest month* & 3 & Climatic \\
Precipitation of warmest quarter* & 2.7 & Climatic \\
Annual PET & 1.3 & Climatic \\
Mean diurnal range* & 1.3 & Climatic \\
PET of driest quarter* & 1.1 & Climatic \\
\hline
\end{tabular}

$1 *$ indicates variables with projection data. For LULC, only the category of urban had projection data.

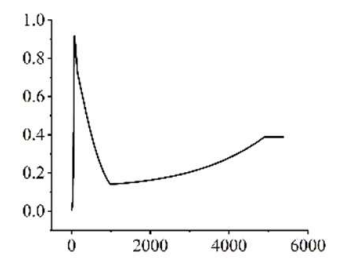

Precipitation of coldest quarter ( $\mathrm{mm})$
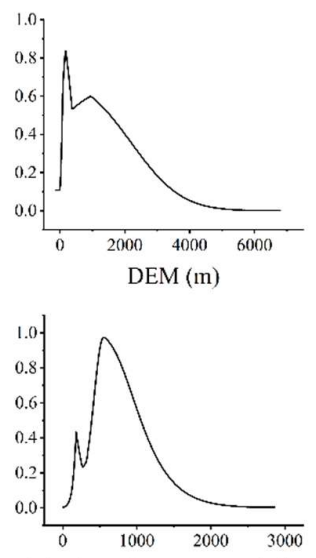

Precipitation of wettest month $(\mathrm{mm})$ Precipitation of warmest quarter $(\mathrm{mm})$

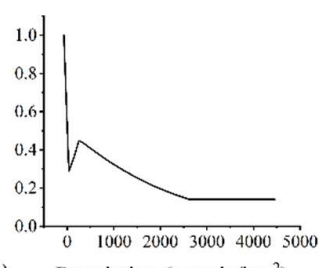

Population (people $/ \mathrm{km}^{2}$ )
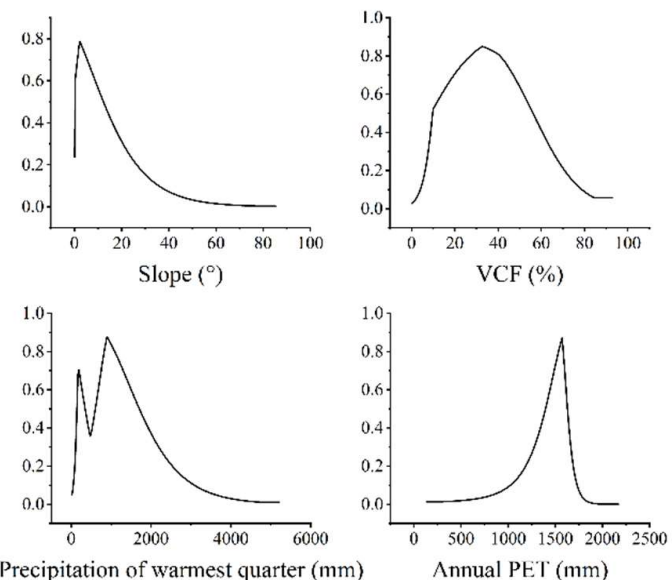
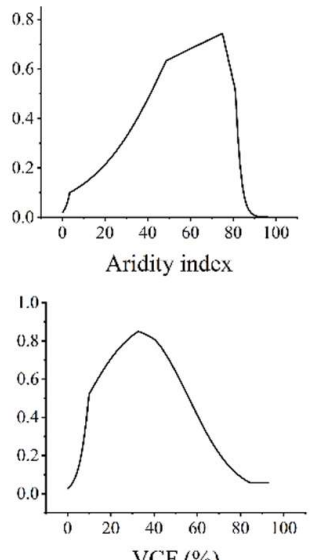

Annual PET $(\mathrm{mm})$
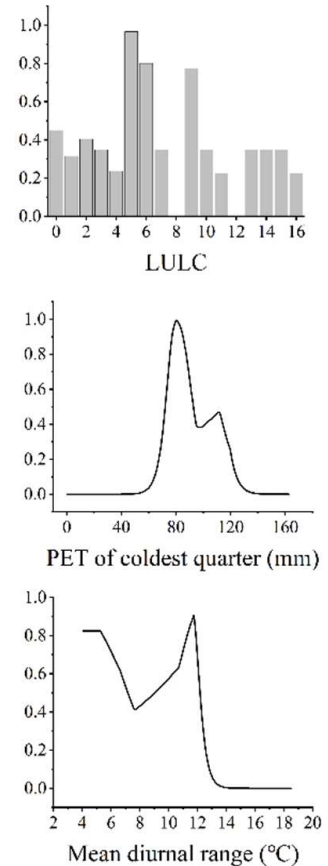
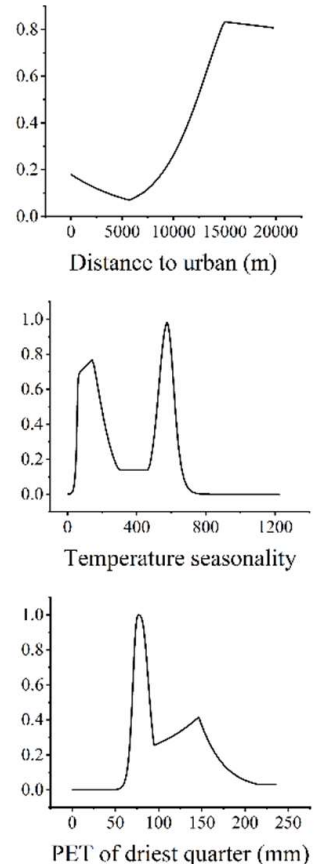

Figure 4. Response curves for the 15 environmental variables.

\subsection{Current and Future Potential Habitats of Asian Elephants}

The area of potential habitats for elephants in the study area was about $516,753 \mathrm{~km}^{2}$ in total, mainly located in southern and northeastern India, southern Nepal, most areas of Sri Lanka, and southern Thailand (Figure 5). The protected areas defined by IUCN had a total area of $627,367 \mathrm{~km}^{2}$, which was $21.4 \%$ larger than the modeled potential suitable habitats. The intersecting area between these two kinds of habitats was only $159,726 \mathrm{~km}^{2}$. This difference probably lay in the fact that the modeled potential habitats were derived from elephant occurrence data, while the IUCN-protected areas were artificially delimited regions. The modeled potential habitats could be reserved to be used as protected areas for Asian elephants. 


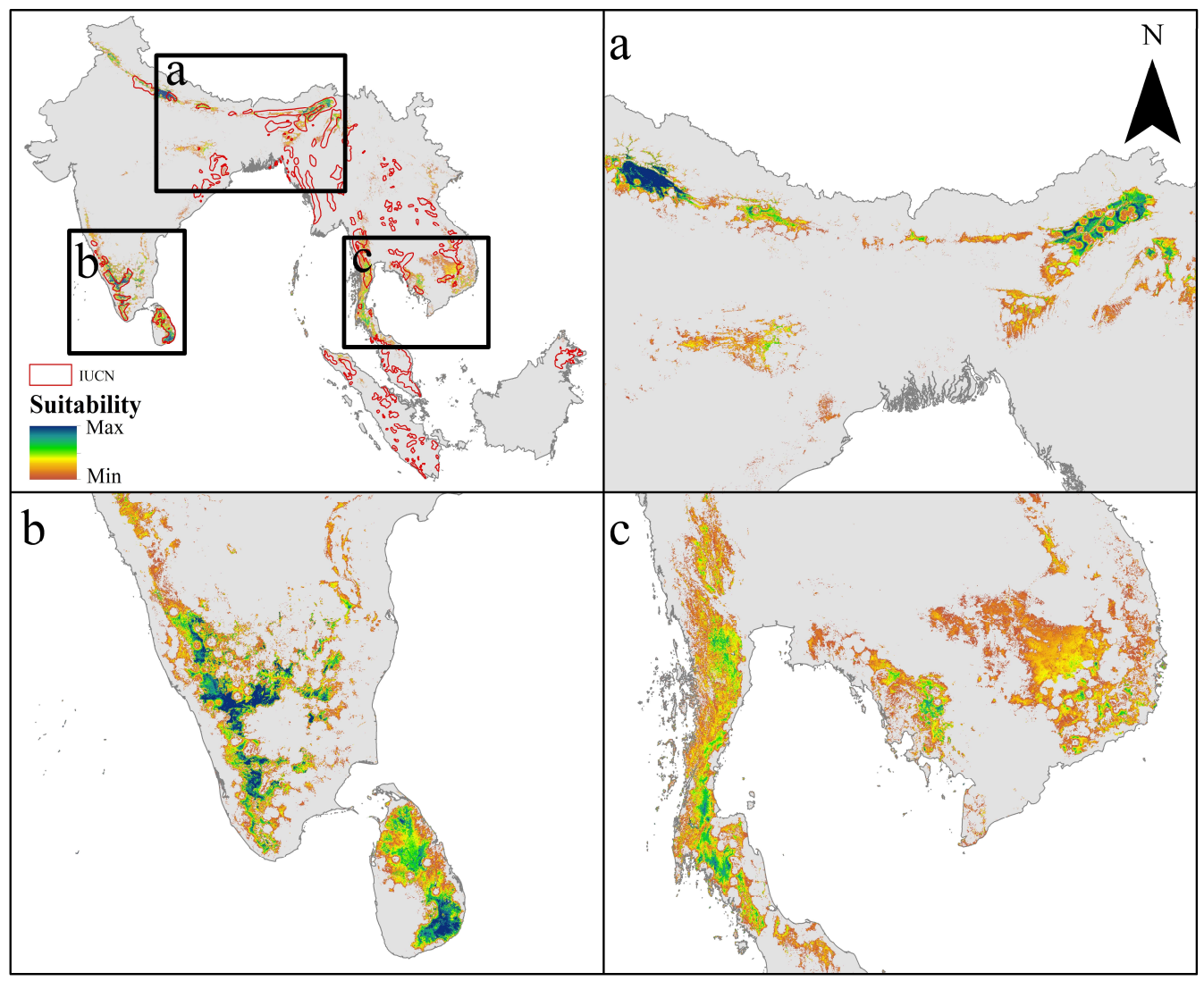

Figure 5. Habitat suitability mapped by MaxEnt and the distribution of Asian elephants mapped by IUCN.

The current potential distribution of elephants was superposed with the potential distribution in future scenarios to obtain the spatial change of habitats (Figure 6). The results indicated that the spatial changes in the potential distribution of elephants would display the same trend under four scenarios. The suitable area increased initially and then decreased at the 2050 or 2070 mark (Figure 7). The modeled suitable areas were mainly located in India and the border of Thailand, Myanmar, and Laos, expanding northward, while the decrease mainly occurred in Thailand. 


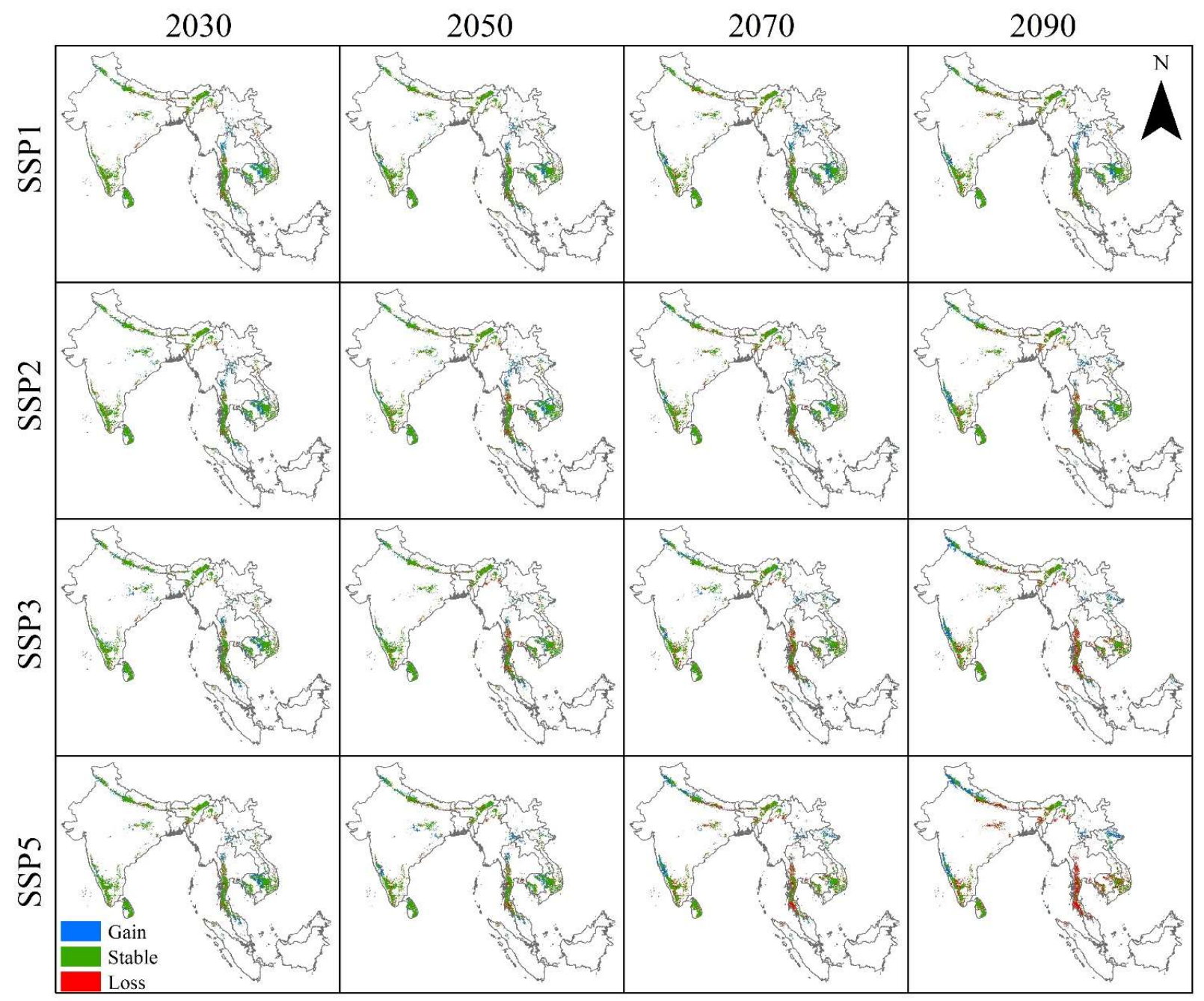

Figure 6. Future projections changes from MaxEnt for potential habitats for Asian elephants.

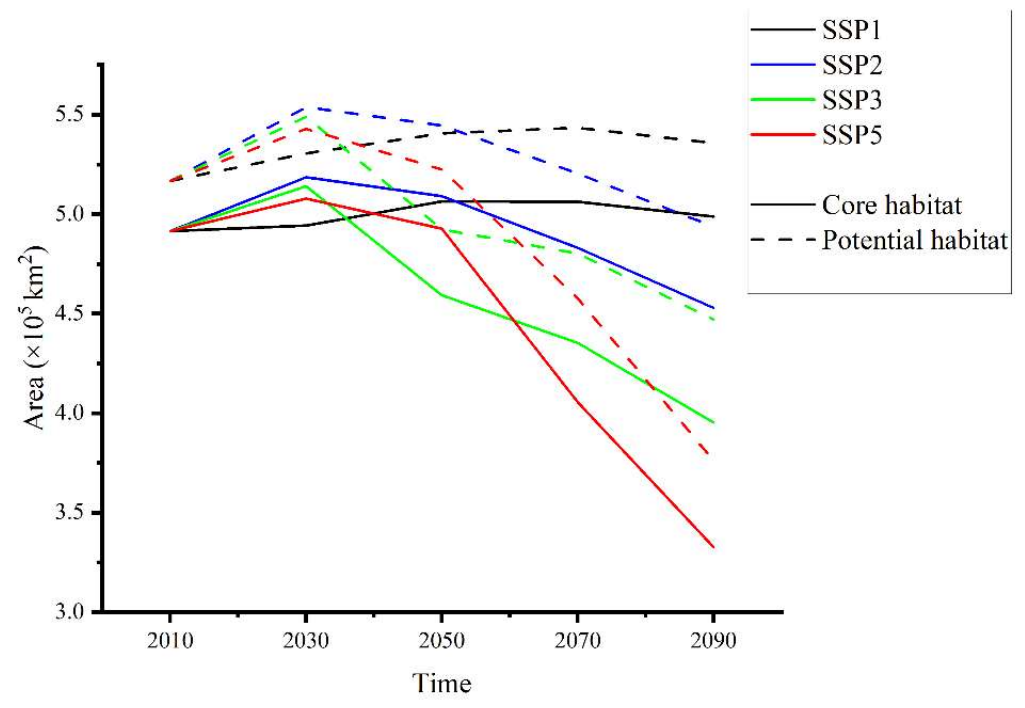

Figure 7. Areas of potential and core habitats. 


\subsection{Identification of the Core Habitats}

Core habitats were considered to be large, contiguous key areas with a high degree of suitability. We used the Core Mapper tool to delineate the core habitats of elephants under all 17 scenarios ( 1 for current and 16 for the next four periods under four different scenarios). We calculated the mean suitability in each core habitat patch (Figure 8). The modeled current core habitats were around $491,455 \mathrm{~km}^{2}$. Several core habitats with high suitability and large areas were distributed in India, Sri Lanka, and Nepal. The core habitats located in Southeast Asia had low suitability. The future projection under different scenarios showed that the changes in the core habitats displayed the same trend as the changes in the potential habitats (Figure 7). We compared future core habitats and the current core habitats and found that the core habitats remained relatively stable under the SSP1 scenario, while the core habitats experienced significant loss under the SSP5 scenario (Figure 9).

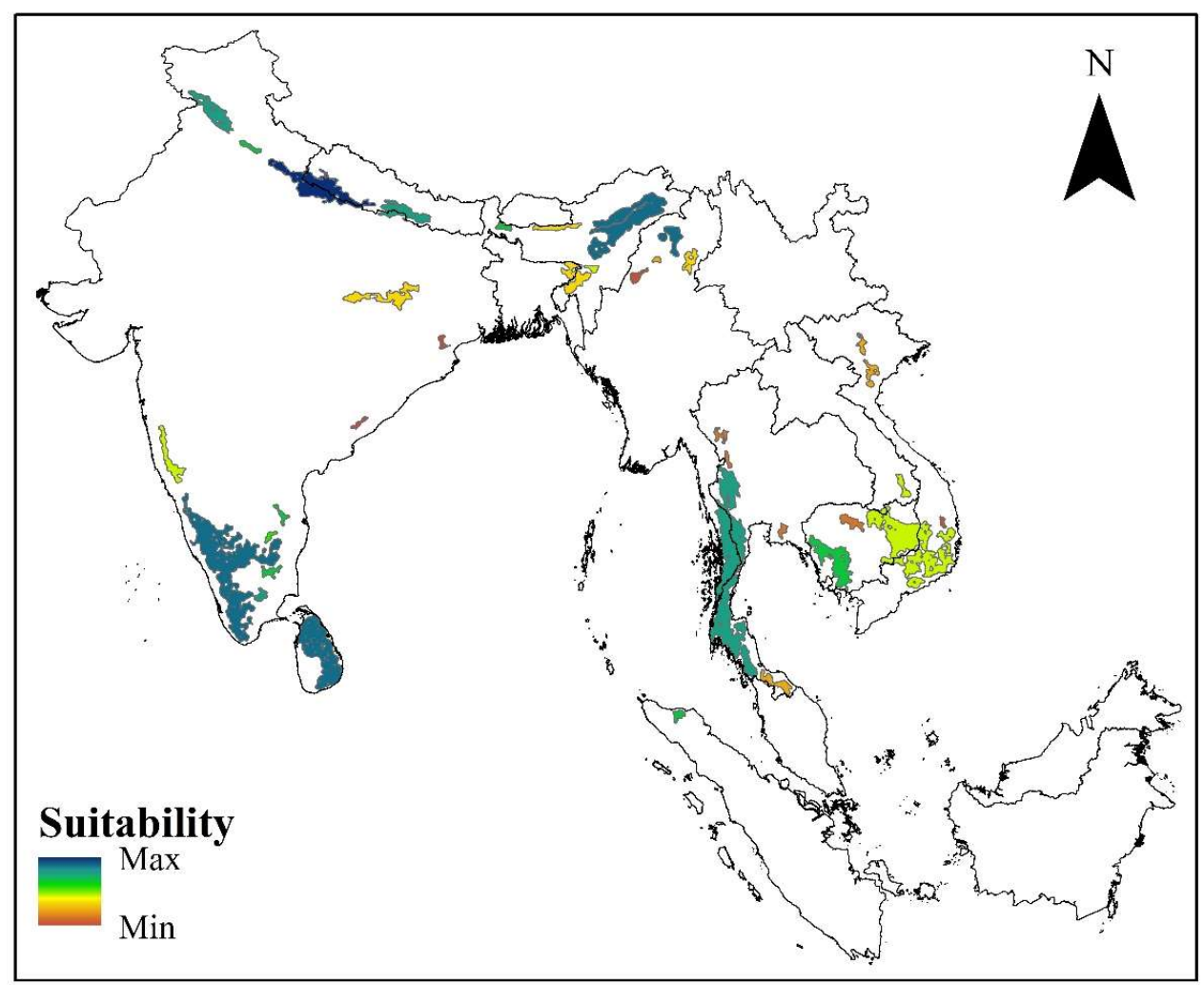

Figure 8. Average suitability in each core habitat patch. 


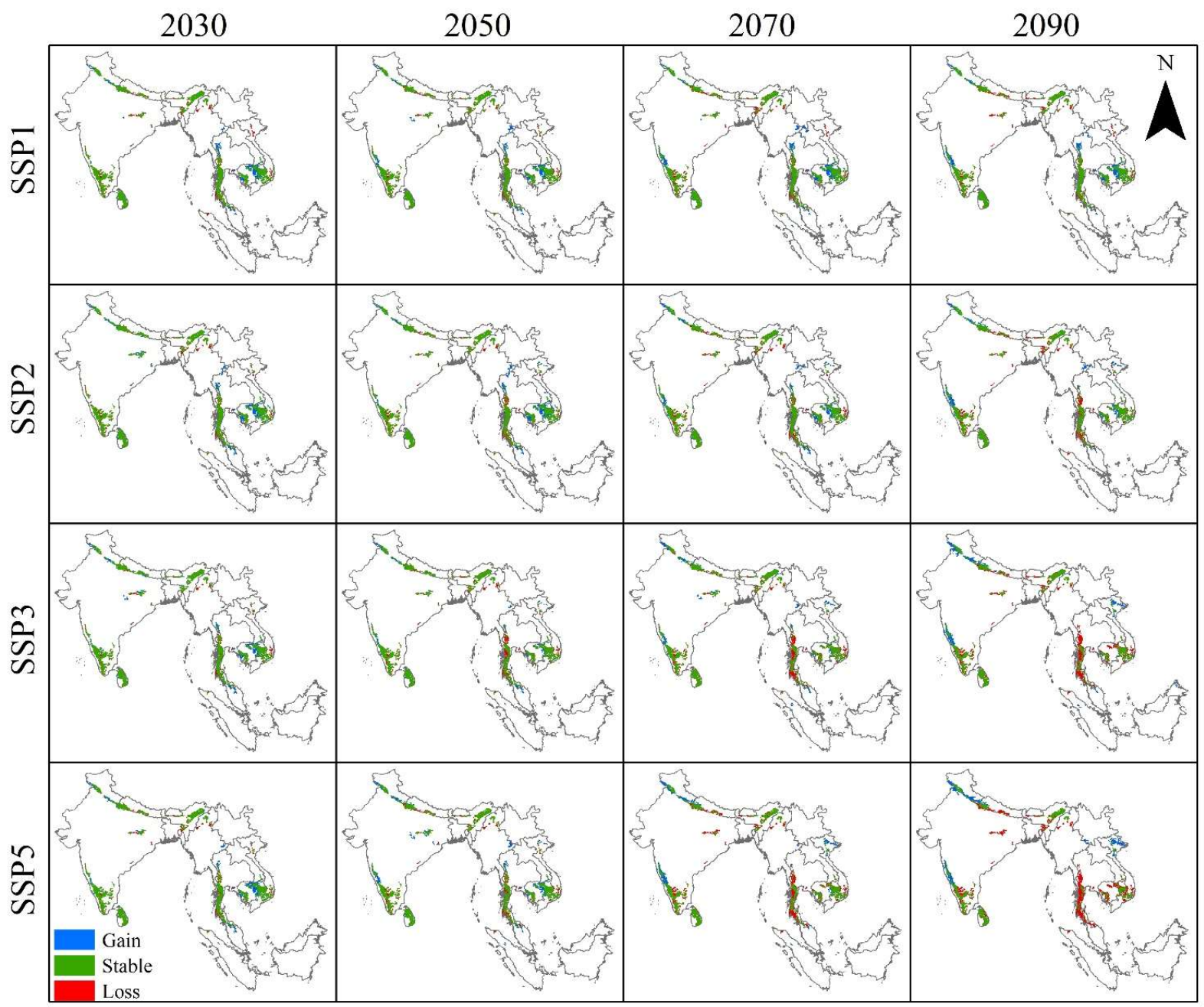

Figure 9. Future changes in MaxEnt projections for core habitats for Asian elephants.

\subsection{Human Footprint Mapping}

We mapped the HF in South and Southeast Asia during 2000-2018 (Figure 10). In core habitats for Asian elephants, the human footprint continued to increase over the 19 years studied, but the changing rate slowed down in recent years (Figure 11). The core habitats located in India had high HF values, and core habitats in other regions had low HF values (Figures 10 and 12(a)). We calculated the changing rate of HF using the least-squares regression method (Figure 12(b)). The HF's major regions that changed substantially were the core habitats with low HF values, such as Vietnam and Cambodia. The core habitats with higher HF values in southern India and Sri Lanka changed slightly. 


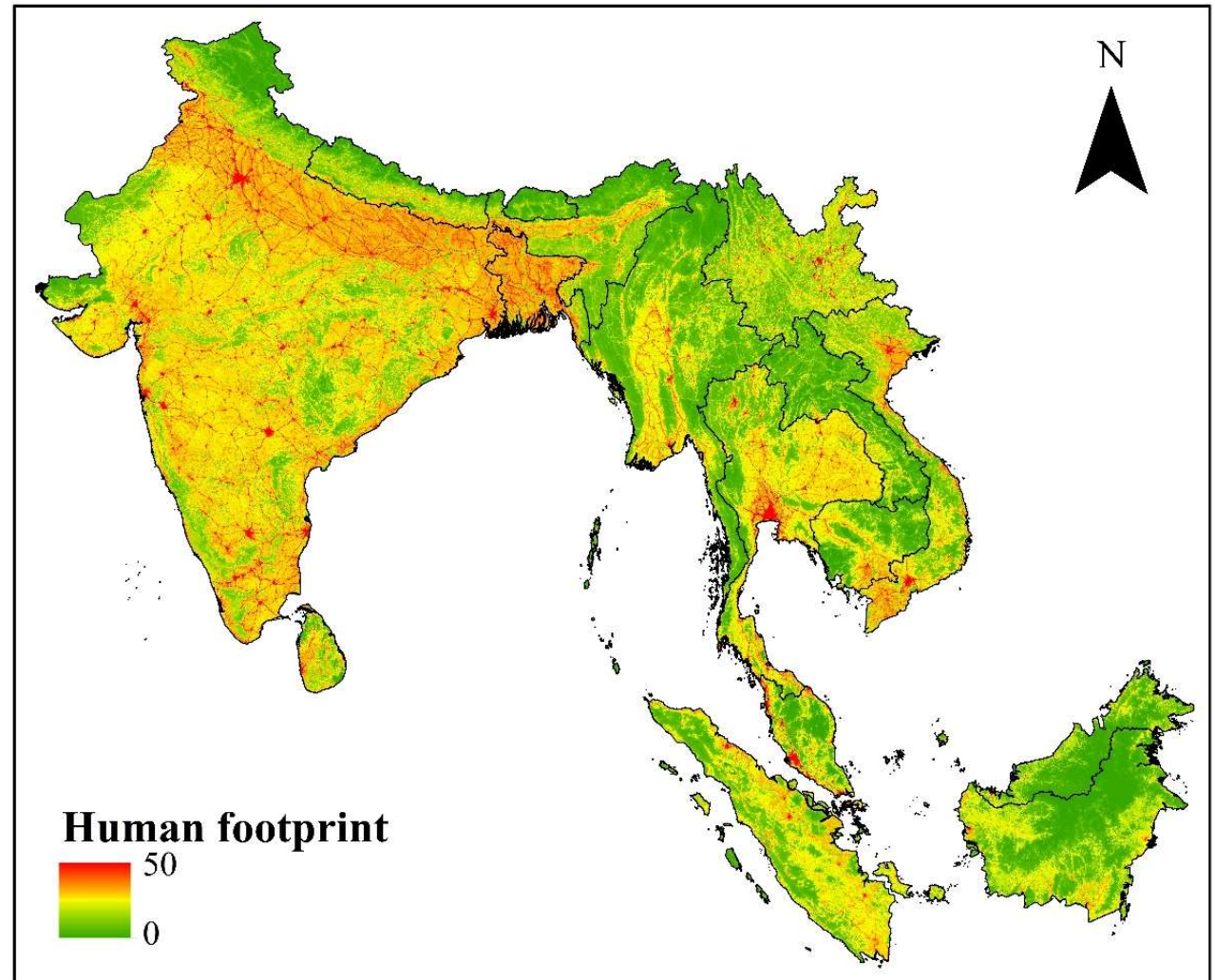

Figure 10. HF map of the study area in 2010.

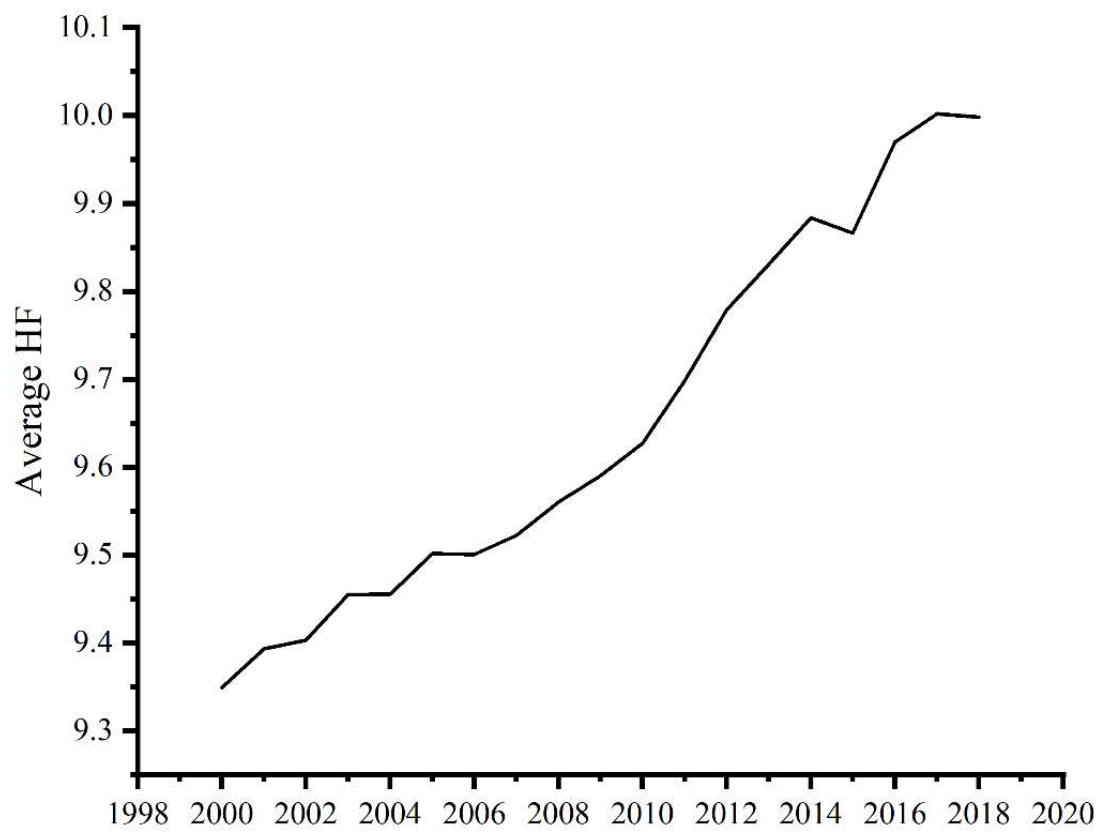

Time

Figure 11. Average HF of core habitats from 2000 to 2018. 


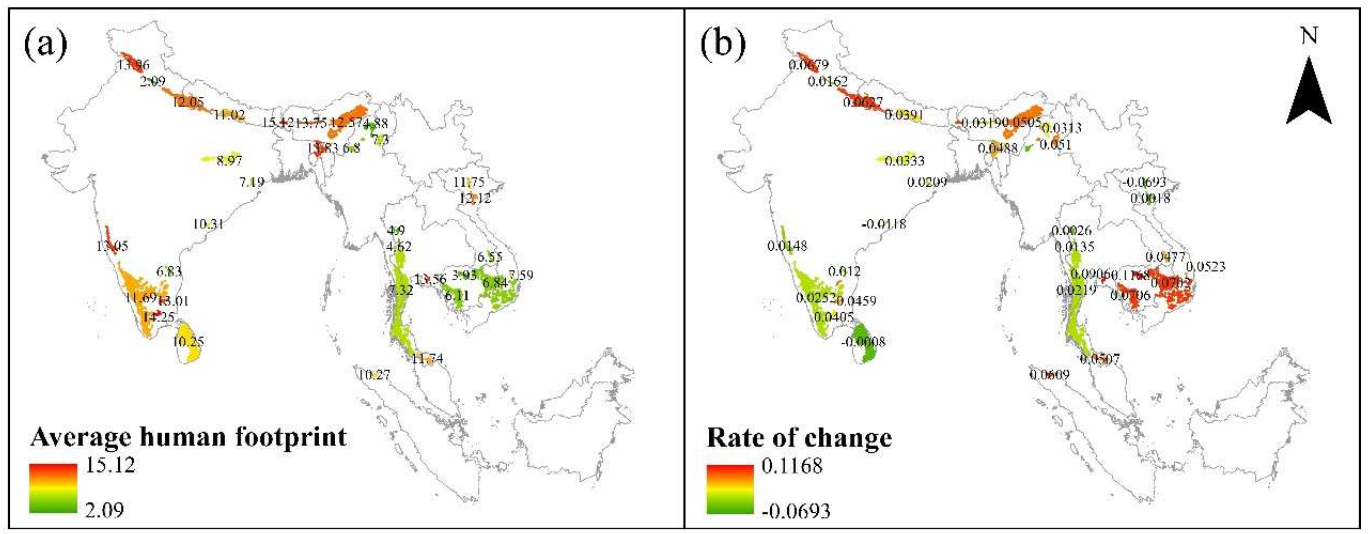

Figure 12. Average human footprint (a) and the rate of change within each core habitat (b).

\subsection{Gap analysis}

The area of current core habitats intersected by the existing PAs was $122,008 \mathrm{~km}^{2}$, while the area of core habitats outside the PAs was $369,447 \mathrm{~km}^{2}$. The area of protected core habitats only accounted for $24.83 \%$ of the protected areas, and $75.17 \%$ of the core habitats were not considered as protected areas (Figure 13).

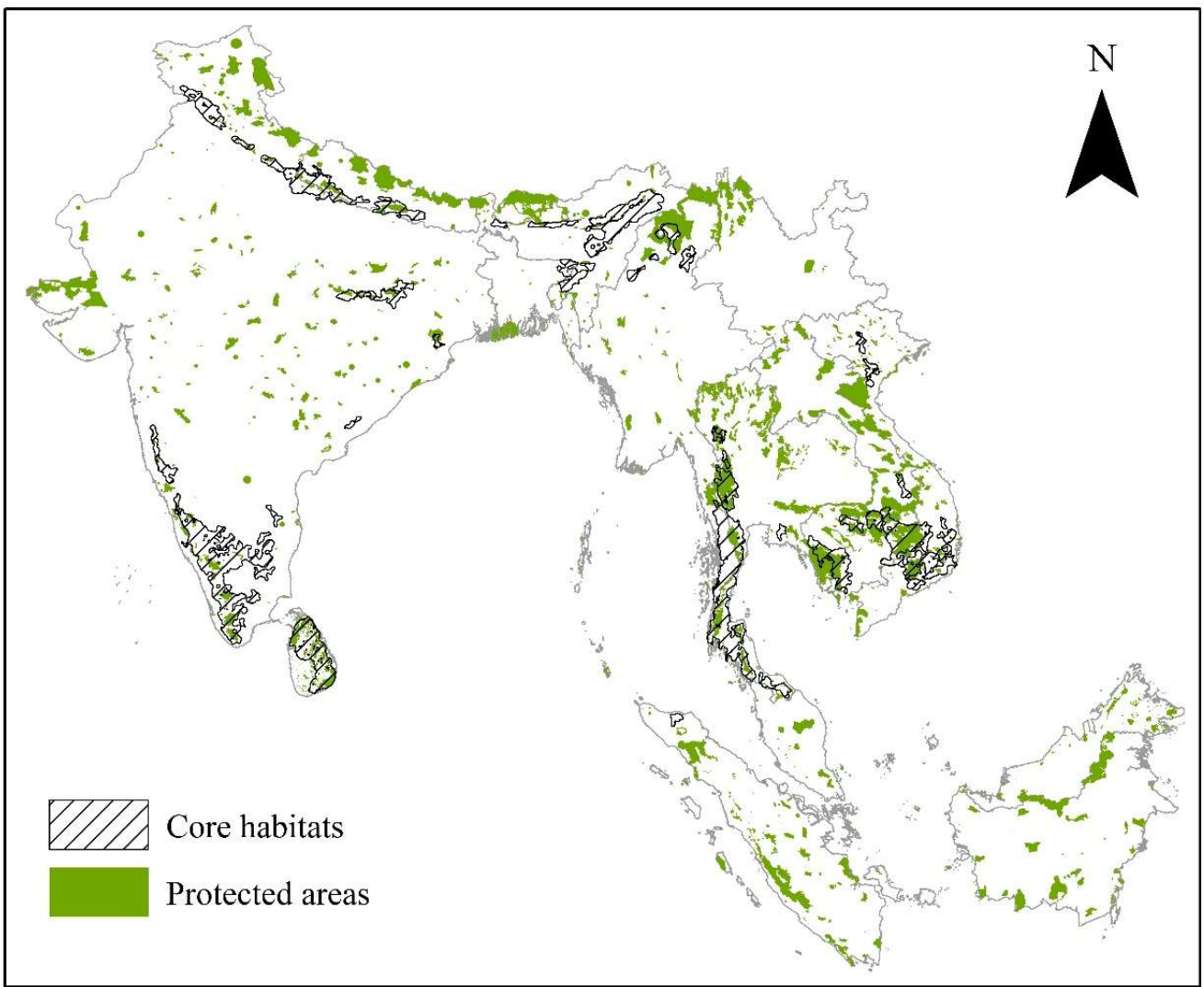

Figure 13. Current distribution of protected areas and core habitats.

We also evaluated the protection efficiency for existing protected areas in protecting the core habitats (Figure 14). Overall, the protection efficiency of the existing protected areas increased by the 2030s under all scenarios, with the highest value of $28.34 \%$ under the SSP1 scenario. Even under the SSP5 scenario by the 2090s, the conservation efficiency 
was still shown to be $23.73 \%$, with a lower rate of decrease. We combined all the core habitats under all 17 scenarios and identified approximately $219,545 \mathrm{~km}^{2}$ of land as areas that should be protected as a priority (Figure 15), which could provide a basis for the establishment of future PAs.

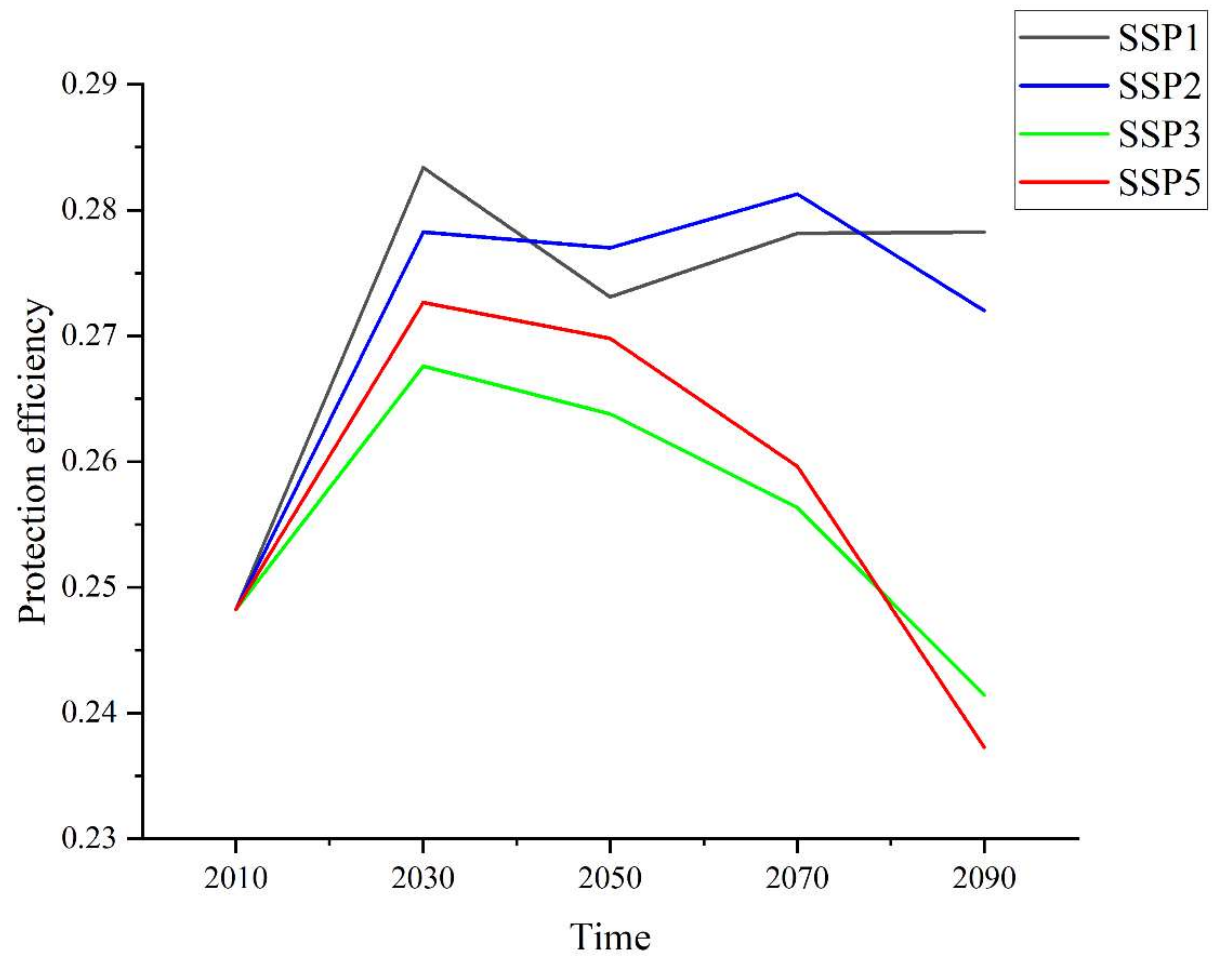

Figure 14. Protection efficiency for the core habitats. 


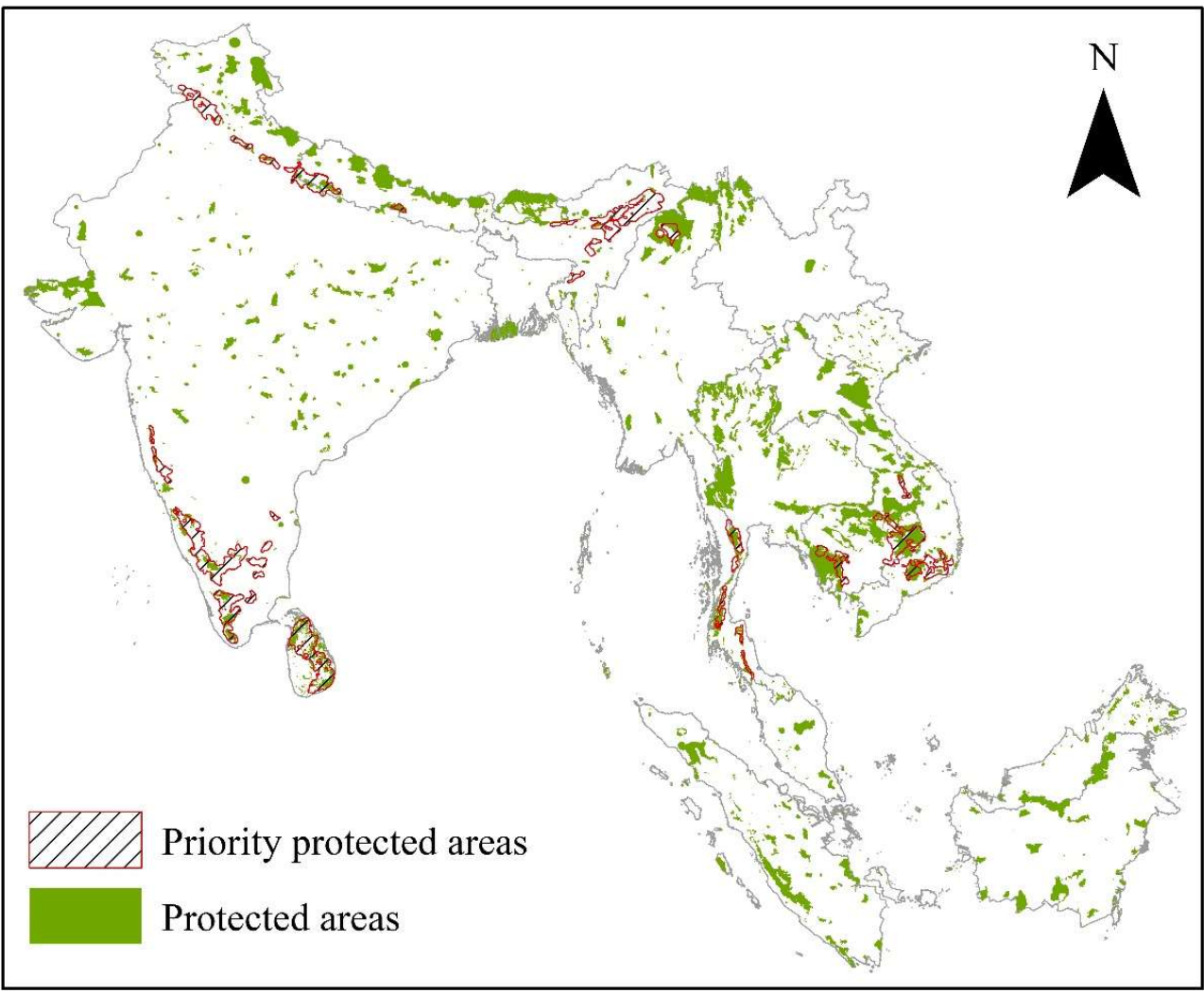

Figure 15. Distribution of areas that should be protected as a priority for Asian elephants.

\section{Discussion}

\subsection{Habitats Shift Caused by Climate Change}

Among 15 variables, 9 climatic variables accounted for 55.1\% contribution, 3 human activity variables accounted for 33.2\%, 2 vegetation variables accounted for $9.1 \%$, and 2 topographic variables accounted for $8 \%$. Based on the currently available data and model configuration, the hydrometeorological variables were identified as the most important factors in the spatial distribution of elephant habitats, which agrees with the results of a previous study [25]. Historical documents also demonstrated that climate change has led to a significant shift in the distribution of elephant habitats over the last few centuries [3]. Such habitat shifts will continue to occur in the future and will pose great challenges to the conservation of elephants.

Forage and water availability are critical for elephant survival [17]. In this study, the precipitation of coldest quarter was determined as the key bioclimatic variable. The importance of the bioclimatic conditions with regard to controlling Asian elephant distribution lies with the fact that bioclimate affects vegetation's spatial pattern and its productivity [93]. The precipitation of the coldest quarter was not considered in a previous study [25], probably because the previous investigations only focused on some specific regions, where the spatial variation of the precipitation of coldest quarter was not significant in such areas. However, when we expanded the study area to the whole of South and Southeast Asia, the spatial differences of this variable would be highlighted. In a previous study, the AET was commonly deemed as the most important bioclimatic variable, possibly due to its local importance, especially in relatively dry regions [25]. However, in our study, most of the study area (especially potential and core habitat areas) is located in hot-wet regions, and therefore, it has a weak contribution and was removed in model-based variable selection. In fact, the contribution of the AET was reflected in the aridity index, which contains information pertaining to the AET [25]. Overall, our results 
demonstrate the importance of bioclimatic conditions with regard to the habitat of Asian elephants, and the response curves showed that elephants prefer places with relatively low precipitation as well as higher PET.

The response of LULC and the 30\% threshold value of VCF for elephant habitats suggested that elephants prefer sites with low forest density, such as mixed forest, shrub, and grassland, which elephants prefer to feed on $[5,94,95]$.

Under future climate change scenarios, the spatial transformation of elephants' habitats showed a trend of northern migration overall (Figure 6). Meanwhile, habitats in the southern part showed degradation, especially under the SSP585 scenario in 2090, with an overall potential habitat reduction of about $25 \%$. Long-term meteorological data projected that the temperature would continue to rise in the future, which would strengthen the Indian monsoon [96], causing increase in evaporative demand and water availability. This would cause elephants to move northward and to higher altitudes, probably resulting in the shrinkage or complete loss of elephant habitats in central India (Figure 6). Moreover, we projected a similar shift to higher latitudes and higher altitudes in Southeast-Asian countries (Figure 6).

\subsection{Habitats Compression Driven by Human Disturbance}

Human activities are typically the main threats to endangered species [97]. The human modification of the natural environment significantly affects the population of different species. According to our modeling results, the human population was found to be the most important component of human activities in affecting the suitability of habitats for Asian elephants. Within its habitat range, the Asian elephant faces threats caused by increased proximity to humans, including poaching and conflict arising from human-elephant interactions [62,98-102]. In Karnataka, Kerala, and Tamil Nadu, where the world's largest Asian elephant populations are distributed, the main threat to the longterm conservation of elephants comes from human disturbance [5]. Elephants' responses to human populations and the distance to urban areas showed that elephant should be prevented from experiencing human disturbance [42]. Urban expansion, especially under the SSP585 scenario in the 2090s, showed that the elephant's habitats would become more fragmented (Figure 6).

Our results showed that the human footprint value increased rapidly in Vietnam and Cambodia due to the massive local deforestation and rapid expansion of cultivated land. Although the human footprint value growth in India and Sri Lanka was not significant, it reached a relatively high level. Native forest loss and land degradation, which affect about $18 \%$ of India's territory [103,104], are major threats to its biodiversity and will decrease the availability of forage for wild herbivores [105,106]. Higher levels of importance should be attached to human pressure in future endeavors to protect the habitats of Asian elephants.

\subsection{More PAs Need to be Established}

Our gap analysis showed that the existing PAs were inadequate in protecting elephants, and there were many conservation gaps. The efficiency of existing PAs under different scenarios indicated that most of the existing protected areas intersected with the modeled core habitats are stable priority habitats for elephants. However, the total protection efficiency was relatively low, because the remaining $75.17 \%$ of the core habitats lie outside the current PAs.

As we mentioned in the analyses, the core habitat was composed of large, contiguous key areas with high suitability. Thus, the modeled priority habitat areas from the MaxEnt could be reliable habitats for protected areas for Asian elephants in future planning (Figure 16). The modeled core habitats were the most suitable areas for elephant habitats when taking into account various natural and anthropogenic conditions. We suggested that the core habitat areas could be considered as a priority in the future [107]. 


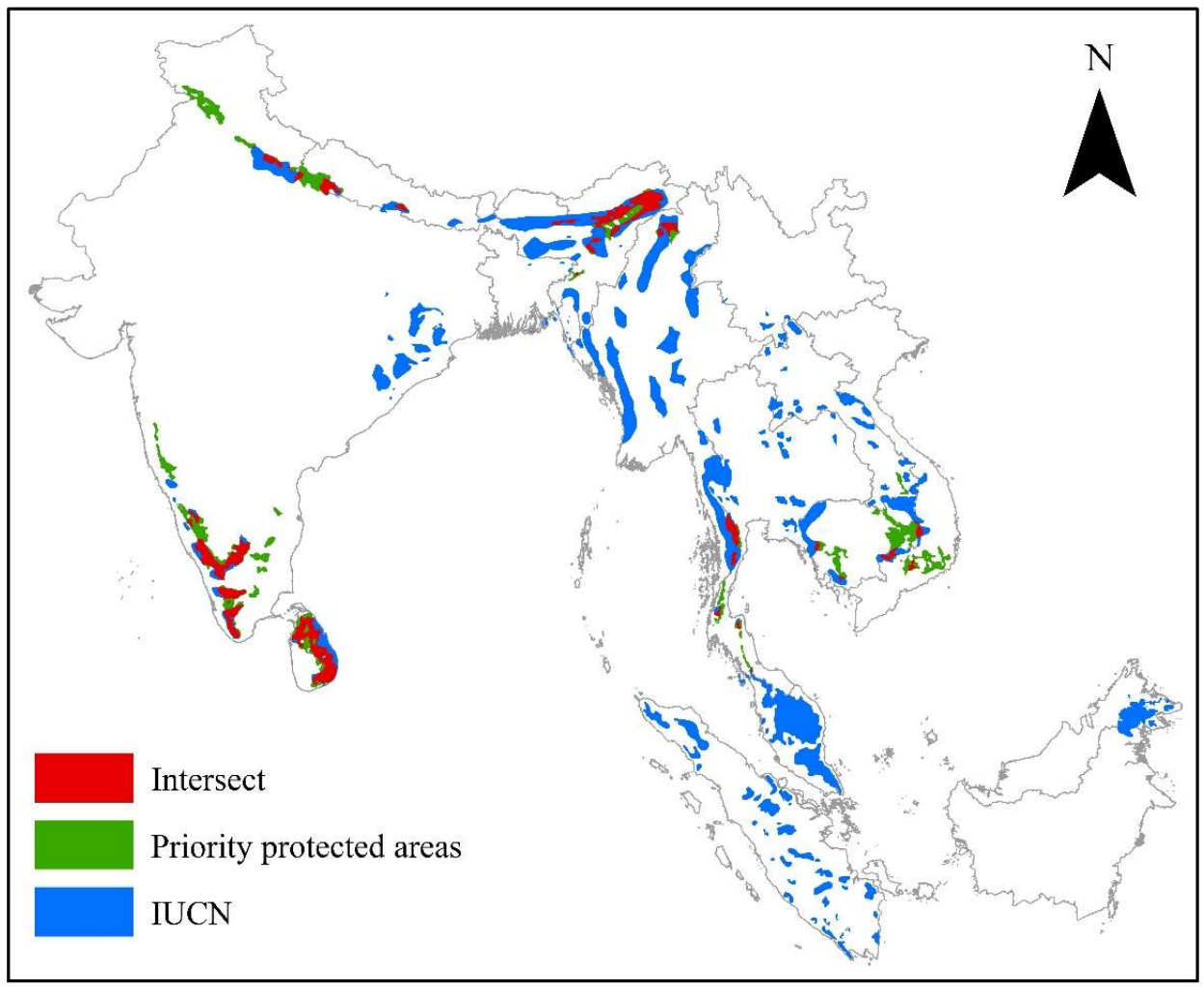

Figure 16. Proposed extended protected areas for Asian elephants; intersection of our suggested areas that should be protected as a priority with the IUCN Asian elephant range.

\subsection{Limitations of the current study}

The MaxEnt model is one of the most widely used species distribution models. Many studies have confirmed that MaxEnt is reliable in modeling the potential distribution of species [108,109]. However, the MaxEnt model is greatly dependent on the field observation data. In areas without observed occurrence events (e.g., Yunnan and Southeast Asia), the modeled potential and core habitat did not match well with the actual distribution. More field investigations are required, especially in Southeast Asia, in which there was less occurrence data. The modeled distribution range did not match well with the ranges provided by the IUCN in some places, because we mapped all the suitable areas where Asian elephants may not live. In contrast, the IUCN mapped the approximate range of the extant Asian elephants. Most currently protected areas are objectively manipulated areas with administrative planning.

In addition, the accuracy of the model's projections for the future were highly dependent on the precision and resolution of the future projection data. For example, VCF, population, and LULC variables were set to be static when making projections for the future because these datasets were generally unavailable at present. As the results showed, human disturbance is quite important. The best way to determine the future effects of human disturbance and climate change on the habitats of Asian elephants is to place one type of variable as constant in the model and then compare the rate of habitat change. In any case, such experiments could not be performed because high-quality human disturbance projection datasets are not available. Although the absence of projection data inevitably affected the accuracy of the projections, in this study, the modeling results were demonstrated as sensible in the current stage [25].

The establishment of PAs often requires a great deal of justification and sophisticated design, while our analysis only focused on analyzing the potential hotspots for elephant 
habitats without considering the social and economic costs and governance. Future studies are expected to involve more variables and practical scenarios to enhance the rationality of these findings.

\section{Conclusion}

This study identified the potential habitat area for Asian elephants using the MaxEnt model. The Core Mapper Tool was used to identify the core habitats of Asian elephants. The results showed that the habitat of Asian elephant will experience a trend of expansion and then shrink due to the backdrop of global change, with a northward shift overall. We constructed the annual human footprint in the study area from 2000 to 2018, which showed a flat change in areas where the human footprint reached a high level and a rapid growth in areas with a low human footprint in Southeast Asia. Protection efficiency was assessed using gap analysis, indicating that the existing protected areas are suitable, but measures are still needed to expand these protected areas. A total of $219,545 \mathrm{~km}^{2}$ of land was identified as areas that should be protected as a priority; this was achieved by overlaying all of the core habitats under all of the scenarios. Our work is of great significance to the conservation of Asian elephants.

Author Contributions: Conceptualization, Y.M.; methodology, W.Y.; software, W.Y.; validation, W.Y.; formal analysis, W.Y.; investigation, Y.M.; resources, Y.M. and L.J.; data curation, W.Y.; writing-original draft preparation, W.Y.; writing-review and editing, Y.M., L.J., Y.T., H.L., and S.W.; visualization, W.Y.; supervision, L.J.; project administration, L.J.; funding acquisition, Y.M. and Z.S. All authors have read and agreed to the published version of the manuscript.

Funding: This research was funded by the Aerospace Information Research Institute, Chinese Academy of Sciences (grant number Y951150Z2F); the National Natural Science Foundation of China (grant number 42071312); the Strategic Priority Research Program of the Chinese Academy of Sciences (grant number XDA19030100).

Data Availability Statement: The data presented in this study are available on request from the corresponding author.

Acknowledgments: The authors are grateful for the comments from anonymous reviewers and the editors.

Conflicts of Interest: The authors declare no conflict of interest.

\section{References}

1. Blicharska, M.; Smithers, R.J.; Mikusinski, G.; Ronnback, P.; Harrison, P.A.; Nilsson, M.; Sutherland, W.J. Biodiversity's contributions to sustainable development. Nature Sustainability 2019, 2, 1083-1093, doi:10.1038/s41893-019-0417-9.

2. Cardinale, B.J.; Duffy, J.E.; Gonzalez, A.; Hooper, D.U.; Perrings, C.; Venail, P.; Narwani, A.; Mace, G.M.; Tilman, D.; Wardle, D.A.; et al. Biodiversity loss and its impact on humanity. Nature 2012, 486, 59-67, doi:10.1038/nature11148.

3. Olivier, R. Distribution and Status of the Asian Elephant. Oryx 1978, 14, 379 - 424, doi:10.1017/S003060530001601X.

4. Menon, V.; Tiwari, S.K. Population status of Asian elephants Elephas maximus and key threats. International Zoo Yearbook 2019, 53, 17-30, doi:10.1111/izy.12247.

5. Baskaran, N. An overview of Asian Elephants in the Western Ghats, southern India: implications for the conservation of Western Ghats ecology. Journal of Threatened Taxa 2013, 5, 4854-4870, doi:10.11609/JoTT.o3634.4854-70.

6. Alamgir, M.; Mukul, S.A.; Turton, S.M. Modelling spatial distribution of critically endangered Asian elephant and Hoolock gibbon in Bangladesh forest ecosystems under a changing climate. Applied Geography 2015, 60, 10-19, doi: 10.1016/j.apgeog.2015.03.001.

7. Baskaran, N.; Kannan, G.; Anbarasan, U.; Thapa, A.; Sukumar, R. A landscape-level assessment of Asian elephant habitat, its population and elephant-human conflict in the Anamalai hill ranges of southern Western Ghats, India. Mammalian Biology 2013, 78, 470-481, doi:10.1016/j.mambio.2013.04.007.

8. Chen, S.; Sun, G.Z.; Wang, Y.; Huang, C.; Chen, Y.; Liu, P.; Deng, Y.; Cao, D.F.; Zhang, M.X.; Ong, S.; et al. A multistakeholder exercise to identify research and conservation priorities for Asian elephants in China. Global Ecology and Conservation 2021, 27, doi:10.1016/j.gecco.2021.e01561. 
9. Fernando, P.; Wikrarnanayake, E.D.; Janaka, H.K.; Jayasinghe, L.K.A.; Gunawardena, M.; Kotagama, S.W.; Weerakoon, D.; Pastorini, J. Ranging behavior of the Asian elephant in Sri Lanka. Mammalian Biology 2008, 73, 2-13, doi:10.1016/j.mambio.2007.07.007.

10. Krishnan, V.; Kumar, M.A.; Raghunathan, G.; Vijayakrishnan, S. Distribution and Habitat Use by Asian Elephants (Elephas maximus) in a Coffee-Dominated Landscape of Southern India. Tropical Conservation Science 2019, 12, doi:10.1177/1940082918822599.

11. Kumar, M.A.; Mudappa, D.; Raman, T.R.S. Asian elephant Elephas maximus habitat use and ranging in fragmented rainforest and plantations in the Anamalai Hills, India. Tropical Conservation Science 2010, 3, 143-158, doi:10.1177/194008291000300203.

12. Madhusudan, M.D.; Sharma, N.; Raghunath, R.; Baskaran, N.; Bipin, C.M.; Gubbi, S.; Johnsingh, A.J.T.; Kulkarni, J.; Kumara, H.N.; Mehta, P.; et al. Distribution, relative abundance, and conservation status of Asian elephants in Karnataka, southern India. Biological Conservation 2015, 187, 34-40, doi:10.1016/j.biocon.2015.04.003.

13. Nad, C.; Roy, P.R.; Roy, D.T.B. Human elephant conflict in changing land-use land-cover scenario in and adjoining region of Buxa tiger reserve, India. Environmental Challenges 2021, 100384, doi:10.1016/j.envc.2021.100384.

14. Neupane, D.; Kwon, Y.; Risch, T.S.; Williams, A.C.; Johnson, R.L. Habitat use by Asian elephants: Context matters. Global Ecology and Conservation 2019, 17, doi:10.1016/j.gecco.2019.e00570.

15. Puyravaud, J.P.; Cushman, S.A.; Davidar, P.; Madappa, D. Predicting landscape connectivity for the Asian elephant in its largest remaining subpopulation. Animal Conservation 2017, 20, 225-234, doi:10.1111/acv.12314.

16. Santiapillai, C.; Chambers, M.R.; Ishwaran, N. Aspects of the Ecology of the Asian Elephant Elephas-Maximus L in the RuhunaNational-Park, Sri-Lanka. Biological Conservation 1984, 29, 47-61, doi:10.1016/0006-3207(84)90013-2.

17. SUKUMAR, R. A brief review of the status, distribution and biology of wild Asian elephants Elephas maximus. International Zoo Yearbook 2006, 40, 1-8, doi:10.1111/j.1748-1090.2006.00001.x.

18. Pradhan, N.M.B.; Wegge, P. Dry season habitat selection by a recolonizing population of Asian elephantsElephas maximus in lowland Nepal. Acta Theriologica 2007, 52, 205-214, doi:10.1007/bf03194216.

19. Neupane, D.; Kwon, Y.; Risch, T.S.; Johnson, R.L. Changes in habitat suitability over a two decade period before and after Asian elephant recolonization. Global Ecology and Conservation 2020, 22, doi:10.1016/j.gecco.2020.e01023.

20. Li, W.W.; Yu, Y.; Liu, P.; Tang, R.C.; Dai, Y.C.; Li, L.; Zhang, L. Identifying climate refugia and its potential impact on small population of Asian elephant (Elephas maximus) in China. Global Ecology and Conservation 2019, 19, doi:10.1016/j.gecco.2019.e00664.

21. Mandal, M.; Das Chatterjee, N. Geospatial approach-based delineation of elephant habitat suitability zones and its consequence in Mayurjharna Elephant Reserve, India. Environment Development and Sustainability 2021, 23, 17788-17809, doi:10.1007/s10668021-01412-1.

22. Bandara, J.S.; Cai, Y. The impact of climate change on food crop productivity, food prices and food security in South Asia. Economic Analysis and Policy 2014, 44, 451-465, doi:10.1016/j.eap.2014.09.005.

23. Supharatid, S.; Nafung, J.; Aribarg, T. Projected changes in temperature and precipitation over mainland Southeast Asia by CMIP6 models. Journal of Water and Climate Change 2021, doi:10.2166/wcc.2021.015.

24. Almazroui, M.; Saeed, S.; Saeed, F.; Islam, M.N.; Ismail, M. Projections of Precipitation and Temperature over the South Asian Countries in CMIP6. Earth Systems and Environment 2020, 4, 297-320, doi:10.1007/s41748-020-00157-7.

25. Kanagaraj, R.; Araujo, M.B.; Barman, R.; Davidar, P.; De, R.; Digal, D.K.; Gopi, G.V.; Johnsingh, A.J.T.; Kakati, K.; Kramer-Schadt, S.; et al. Predicting range shifts of Asian elephants under global change. Diversity and Distributions 2019, 25, 822-838, doi:10.1111/ddi.12898.

26. Vidya, T.N.C.; Thuppil, V. Immediate behavioural responses of humans and Asian elephants in the context of road traffic in southern India. Biological Conservation 2010, 143, 1891-1900, doi:10.1016/j.biocon.2010.04.043.

27. Fernando, P.; Wikramanayake, E.; Weerakoon, D.; Jayasinghe, L.K.A.; Gunawardene, M.; Janaka, H.K. Perceptions and patterns of human-elephant conflict in old and new settlements in Sri Lanka: insights for mitigation and management. Biodiversity and Conservation 2005, 14, 2465-2481, doi:10.1007/s10531-004-0216-z.

28. Goswami, V.R.; Medhi, K.; Nichols, J.D.; Oli, M.K. Mechanistic understanding of human-wildlife conflict through a novel application of dynamic occupancy models. Conserv. Biol. 2015, 29, 1100-1110, doi:10.1111/cobi.12475.

29. Alfred, R.; Ahmad, A.H.; Payne, J.; Williams, C.; Ambu, L.N.; How, P.M.; Goossens, B. Home Range and Ranging Behaviour of Bornean Elephant (Elephas maximus borneensis) Females. Plos One 2012, 7, doi:10.1371/journal.pone.0031400.

30. Neupane, D.; Kwon, Y.; Risch, T.S.; Williams, A.C.; Johnson, R.L. Habitat use by Asian elephants: Context matters. Global Ecology and Conservation 2019, 17, doi:10.1016/j.gecco.2019.e00570.

31. Baskaran, N.; Kannan, G.; Anbarasan, U.; Thapa, A.; Sukumar, R. A landscape-level assessment of Asian elephant habitat, its population and elephant-human conflict in the Anamalai hill ranges of southern Western Ghats, India. Mammalian Biology 2013, 78, 470-481, doi:10.1016/j.mambio.2013.04.007.

32. Elith, J.; Leathwick, J.R. Species Distribution Models: Ecological Explanation and Prediction Across Space and Time. Annual Review of Ecology Evolution and Systematics 2009, 40, 677-697, doi:10.1146/annurev.ecolsys.110308.120159.

33. Wang, G.; Wang, C.; Guo, Z.R.; Dai, L.J.; Wu, Y.Q.; Liu, H.Y.; Li, Y.F.; Chen, H.; Zhang, Y.N.; Zhao, Y.X.; et al. Integrating Maxent model and landscape ecology theory for studying spatiotemporal dynamics of habitat: Suggestions for conservation of endangered Red -crowned crane. Ecological Indicators 2020, 116, doi:10.1016/j.ecolind.2020.106472.

34. Zhang, G.M.; Zhu, A.X.; Windels, S.K.; Qin, C.Z. Modelling species habitat suitability from presence-only data using kernel density estimation. Ecological Indicators 2018, 93, 387-396, doi:10.1016/j.ecolind.2018.04.002. 
35. Wall, J.; Wittemyer, G.; Klinkenberg, B.; LeMay, V.; Blake, S.; Strindberg, S.; Henley, M.; Vollrath, F.; Maisels, F.; Ferwerda, J.; et al. Human footprint and protected areas shape elephant range across Africa. Current Biology 2021, 31, 2437-2445, doi:10.1016/j.cub.2021.03.042.

36. Saranya, K.R.L.; Lakshmi, T.V.; Reddy, C.S. Predicting the potential sites of Chromolaena odorata and Lantana camara in forest landscape of Eastern Ghats using habitat suitability models. Ecological Informatics 2021, 66, 101455, doi:10.1016/j.ecoinf.2021.101455.

37. Araújo, M.B.; New, M. Ensemble forecasting of species distributions. Trends in Ecology E Evolution 2007, 22, 42-47, doi:10.1016/j.tree.2006.09.010.

38. Araújo, M.B.; Whittaker, R.J.; Ladle, R.J.; Erhard, M. Reducing uncertainty in projections of extinction risk from climate change. Global Ecology and Biogeography 2005, 14, 529-538, doi:10.1111/j.1466-822X.2005.00182.x.

39. Radosavljevic, A.; Anderson, R.P. Making better Maxent models of species distributions: complexity, overfitting and evaluation. Journal of Biogeography 2014, 41, 629-643, doi:10.1111/jbi.12227.

40. Merow, C.; Smith, M.J.; Silander Jr, J.A. A practical guide to MaxEnt for modeling species' distributions: what it does, and why inputs and settings matter. Ecography 2013, 36, 1058-1069, doi:10.1111/j.1600-0587.2013.07872.x.

41. Warren, D.L.; Seifert, S.N. Ecological niche modeling in Maxent: the importance of model complexity and the performance of model selection criteria. Ecological Applications 2011, 21, 335-342, doi:10.1890/10-1171.1.

42. Sharma, P.; Panthi, S.; Yadav, S.K.; Bhatta, M.; Karki, A.; Duncan, T.; Poudel, M.; Acharya, K.P. Suitable habitat of wild Asian elephant in Western Terai of Nepal. Ecology and Evolution 2020, 10, 6112-6119, doi:10.1002/ece3.6356.

43. Taher, T.M.; Lihan, T.; Arifin, N.A.T.; Khodri, N.F.; Mustapha, M.A.; Patah, P.A.; Razali, S.H.A.; Nor, S.M. Characteristic of habitat suitability for the Asian elephant in the fragmented Ulu Jelai Forest Reserve, Peninsular Malaysia. Tropical Ecology 2021, 62, 347-358, doi:10.1007/s42965-021-00154-5.

44. de Silva, S.; Wu, T.; Thieme, A.; Johnson, J.; Nyhus, P.; Wadey, J.; Vu, T.; Mossbrucker, A.; Neang, T.; Chen, B.; et al. The Past, Present and Future of Elephant Landscapes in Asia. bioRxiv 2020, doi:10.1101/2020.04.28.066548.

45. Chape, S.; Harrison, J.; Spalding, M.; Lysenko, I. Measuring the extent and effectiveness of protected areas as an indicator for meeting global biodiversity targets. Philosophical Transactions of the Royal Society B-Biological Sciences 2005, 360, 443-455, doi:10.1098/rstb.2004.1592.

46. Swart, C.; Donaldson, J.; Barker, N. Predicting the distribution of Encephalartos latifrons, a critically endangered cycad in South Africa. Biodiversity and Conservation 2018, 27, 1961-1980, doi:10.1007/s10531-018-1519-9.

47. Williams, C., Tiwari, S.K., Goswami, V.R., de Silva, S., Kumar, A., Baskaran, N., Yoganand, K. \& Menon, V. Elephas maximus. The IUCN Red List of Threatened Species 2020: e.T7140A45818198 2020, doi:10.2305/IUCN.UK.2020-3.RLTS.T7140A45818198.en.

48. Divya; Mehrotra, R. Climate change and hydrology with emphasis on the Indian subcontinent. Hydrological Sciences JournalJournal Des Sciences Hydrologiques 1995, 40, 231-242, doi:10.1080/02626669509491406.

49. BN, G. South Asian monsoon. Intraseasonal variability in the atmosphere-ocean climate system 2005, doi:10.1007/978-3-642-13914-7_2.

50. Loo, Y.Y.; Billa, L.; Singh, A. Effect of climate change on seasonal monsoon in Asia and its impact on the variability of monsoon rainfall in Southeast Asia. Geoscience Frontiers 2015, 6, 817-823, doi:10.1016/j.gsf.2014.02.009.

51. GBIF.org (21 October 2020) GBIF Occurrence Download, doi:10.15468/dl.meyzuk.

52. Yang, Z.; Bai, Y.; Alatalo, J.M.; Huang, Z.; Yang, F.; Pu, X.; Wang, R.; Yang, W.; Guo, X. Spatio-temporal variation in potential habitats for rare and endangered plants and habitat conservation based on the maximum entropy model. Sci Total Environ 2021, 784, 147080, doi:10.1016/j.scitotenv.2021.147080.

53. Jarvis A., H.I.R., A. Nelson, E. Guevara. Hole-filled seamless SRTM data V4, International Centre for Tropical Agriculture (CIAT), available from https://srtm.csi.cgiar.org. 2008.

54. Lehner, B.; Verdin, K.L.; Jarvis, A. New global hydrography derived from spaceborne elevation data. Eos, Transactions, American Geophysical Union 2008, 89, 93-94, doi:10.1029/2008EO100001.

55. Didan, K. MOD13A2 MODIS/Terra Vegetation Indices 16-Day L3 Global 1km SIN Grid V006. 2015, doi:10.5067/MODIS/MOD13A2.006.

56. Myneni, R., Knyazikhin, Y., Park, T. MOD15A2H MODIS/Terra Leaf Area Index/FPAR 8-Day L4 Global 500m SIN Grid V006. 2015, doi:10.5067/MODIS/MOD15A2H.006.

57. DiMiceli, C., Carroll, M., Sohlberg, R., Kim, D., Kelly, M., Townshend, J. MOD44B MODIS/Terra Vegetation Continuous Fields Yearly L3 Global 250m SIN Grid V006. 2015, doi:10.5067/MODIS/MOD44B.006.

58. Simard, M.; Pinto, N.; Fisher, J.B.; Baccini, A. Mapping forest canopy height globally with spaceborne lidar. Journal of Geophysical Research-Biogeosciences 2011, 116, doi:10.1029/2011jg001708.

59. ESA. Land Cover CCI Product User Guide Version 2. Available at: maps.elie.ucl.ac.be/CCI/viewer/download/ESACCI-LC-Ph2PUGv2_2.0.pdf. 2017.

60. Tratalos, J.; Fuller, R.A.; Warren, P.H.; Davies, R.G.; Gaston, K.J. Urban form, biodiversity potential and ecosystem services. Landscape and Urban Planning 2007, 83, 308-317, doi:10.1016/j.landurbplan.2007.05.003.

61. Fischer, J.; Brosi, B.; Daily, G.C.; Ehrlich, P.R.; Goldman, R.; Goldstein, J.; Lindenmayer, D.B.; Manning, A.D.; Mooney, H.A.; Pejchar, L.; et al. Should agricultural policies encourage land sparing or wildlife-friendly farming? Frontiers in Ecology and the Environment 2008, 6, 382-387, doi:10.1890/070019.

62. Pant, G.; Dhakal, M.; Pradhan, N.M.B.; Leverington, F.; Hockings, M. Nature and extent of human-elephant Elephas maximus conflict in central Nepal. Oryx 2016, 50, 724-731, doi:10.1017/s0030605315000381. 
63. Scrizzi, A.; Le Bel, S.; La Grange, M.; Cornelis, D.; Mabika, C.T.; Czudek, R. Urban human-elephant conflict in Zimbabwe: a case study of the mitigation endeavour. Pachyderm 2017, 59, 76-85.

64. Adams, T.S.F.; Chase, M.J.; Leggett, K.E.A. Elephant movements in different human land-uses in Chobe District, Botswana. Pachyderm 2020, 62, 74-86.

65. Marcacci, G.; Westphal, C.; Wenzel, A.; Raj, V.; Nölke, N.; Tscharntke, T.; Grass, I. Taxonomic and functional homogenization of farmland birds along an urbanization gradient in a tropical megacity. Global Change Biology 2021, 27, 4980-4994, doi:10.1111/gcb.15755.

66. Hamblin, A.L.; Youngsteadt, E.; López-Uribe, M.M.; Frank, S.D. Physiological thermal limits predict differential responses of bees to urban heat-island effects. Biology Letters 2017, 13, 0125, doi:10.1098/rsbl.2017.0125.

67. Kosicki, J.Z. The impact of artificial light at night on taxonomic, functional and phylogenetic bird species communities in a large geographical range: A modelling approach. Science of The Total Environment 2021, 780, 146434, doi:10.1016/j.scitotenv.2021.146434.

68. Tatem, A.J. WorldPop, open data for spatial demography. Scientific Data 2017, 4, 170004, doi:10.1038/sdata.2017.4.

69. OpenStreetMap contributors contributors, O. Planet dump. 2015, available from https://www.openstreetmap.org.

70. Meijer, J.R.; Huijbregts, M.A.J.; Schotten, K.C.G.J.; Schipper, A.M. Global patterns of current and future road infrastructure. Environmental Research Letters 2018, 13, 064006, doi:10.1088/1748-9326/aabd42.

71. Fick, S.E.; Hijmans, R.J. WorldClim 2: new $1 \mathrm{~km}$ spatial resolution climate surfaces for global land areas. International Journal of Climatology 2017, 37, 4302-4315, doi:10.1002/joc.5086.

72. Title, P.O.; Bemmels, J.B. ENVIREM: an expanded set of bioclimatic and topographic variables increases flexibility and improves performance of ecological niche modeling. Ecography 2018, 41, 291-307, doi:10.1111/ecog.02880.

73. Trabucco, A.Z., Robert J. Global High-Resolution Soil-Water Balance. 2019, doi:10.6084/m9.figshare.7707605.v3.

74. Sheppard, C.S. How does selection of climate variables affect predictions of species distributions? A case study of three new weeds in New Zealand. Weed Research 2013, 53, 259-268, doi:10.1111/wre.12021.

75. Li, Y.C.; Li, M.Y.; Li, C.; Liu, Z.Z. Optimized Maxent Model Predictions of Climate Change Impacts on the Suitable Distribution of Cunninghamia lanceolata in China. Forests 2020, 11, doi:10.3390/f11030302.

76. Phillips, S.J.; Anderson, R.P.; Dudík, M.; Schapire, R.E.; Blair, M.E. Opening the black box: an open-source release of Maxent. Ecography 2017, 40, 887-893, doi:10.1111/ecog.03049.

77. Huang, Z.D.; Bai, Y.; Alatalo, J.M.; Yang, Z.Q. Mapping biodiversity conservation priorities for protected areas: A case study in Xishuangbanna Tropical Area, China. Biological Conservation 2020, 249, doi:10.1016/j.biocon.2020.108741.

78. Peterson, A.T.; Papeş, M.; Soberón, J. Rethinking receiver operating characteristic analysis applications in ecological niche modeling. Ecological Modelling 2008, 213, 63-72, doi:10.1016/j.ecolmodel.2007.11.008.

79. Peterson, A.; Soberón, J.; Pearson, R.; Anderson, R.; Martínez-Meyer, E.; Nakamura, M.; Araújo, M. Ecological Niches and Geographic Distributions, Monographs in Population Biology 2011, 49, doi:10.1515/9781400840670.

80. Chen, G.; Li, X.; Liu, X.; Chen, Y.; Liang, X.; Leng, J.; Xu, X.; Liao, W.; Qiu, Y.a.; Wu, Q.; et al. Global projections of future urban land expansion under shared socioeconomic pathways. Nature Communications 2020, 11, 537, doi:10.1038/s41467-020-14386-x.

81. Voldoire, A.; Saint-Martin, D.; Sénési, S.; Decharme, B.; Alias, A.; Chevallier, M.; Colin, J.; Guérémy, J.-F.; Michou, M.; Moine, M.-P.; et al. Evaluation of CMIP6 DECK Experiments With CNRM-CM6-1. Journal of Advances in Modeling Earth Systems 2019, 11, 2177-2213, doi:10.1029/2019MS001683.

82. Eyring, V.; Bony, S.; Meehl, G.A.; Senior, C.A.; Stevens, B.; Stouffer, R.J.; Taylor, K.E. Overview of the Coupled Model Intercomparison Project Phase 6 (CMIP6) experimental design and organization. Geosci. Model Dev. 2016, 9, 1937-1958, doi:10.5194/gmd-9-1937-2016.

83. Shirk, A.J., B.H. McRae. Gnarly Landscape Utilities: Core Mapper User Guide. 2013, available at: https://circuitscape.org/gnarlylandscape-utilities/.

84. Sukumar, R. The Asian Elephant Ecology and Management. 1993.

85. Venter, O.; Sanderson, E.W.; Magrach, A.; Allan, J.R.; Beher, J.; Jones, K.R.; Possingham, H.P.; Laurance, W.F.; Wood, P.; Fekete, B.M.; et al. Global terrestrial Human Footprint maps for 1993 and 2009. Scientific Data 2016, 3, 160067, doi:10.1038/sdata.2016.67.

86. Sanderson, E.W.; Jaiteh, M.; Levy, M.A.; Redford, K.H.; Wannebo, A.V.; Woolmer, G. The Human Footprint and the Last of the Wild: The human footprint is a global map of human influence on the land surface, which suggests that human beings are stewards of nature, whether we like it or not. BioScience 2002, 52, 891-904, doi:10.1641/0006-3568(2002)052[0891:Thfatl]2.0.Co;2.

87. Theobald, D.M.; Kennedy, C.; Chen, B.; Oakleaf, J.; Baruch-Mordo, S.; Kiesecker, J. Earth transformed: detailed mapping of global human modification from 1990 to 2017. Earth Syst. Sci. Data 2020, 12, 1953-1972, doi:10.5194/essd-12-1953-2020.

88. Ramankutty, N.; Evan, A.T.; Monfreda, C.; Foley, J.A. Farming the planet: 1. Geographic distribution of global agricultural lands in the year 2000. Glob. Biogeochem. Cycle 2008, 22, doi:10.1029/2007gb002952.

89. Lehner, B.; Liermann, C.R.; Revenga, C.; Vorosmarty, C.; Fekete, B.; Crouzet, P.; Doll, P.; Endejan, M.; Frenken, K.; Magome, J.; et al. High-resolution mapping of the world's reservoirs and dams for sustainable river-flow management. Frontiers in Ecology and the Environment 2011, 9, 494-502, doi:10.1890/100125.

90. Chen, Z.Q.; Yu, B.L.; Yang, C.S.; Zhou, Y.Y.; Yao, S.J.; Qian, X.J.; Wang, C.X.; Wu, B.; Wu, J.P. An extended time series (2000-2018) of global NPP-VIIRS-like nighttime light data from a cross-sensor calibration. Earth System Science Data 2021, 13, 889-906, doi:10.5194/essd-13-889-2021.

91. UNEP-WCMC, I. Protected Planet: The World Database on Protected Areas (WDPA), sep2020, Cambridge, UK: UNEP-WCMC and IUCN. Available at: www.protectedplanet.net. 2020. 
92. Steven J. Phillips, M.D., Robert E. Schapire. Maxent software for modeling species niches and distributions (Version 3.4.3). Available from url: http://biodiversityinformatics.amnh.org/open_source/maxent/. Accessed on 2020-6-8.

93. Pramanik, M.; Diwakar, A.K.; Dash, P.; Szabo, S.; Pal, I. Conservation planning of cash crops species (Garcinia gummi-gutta) under current and future climate in the Western Ghats, India. Environment Development and Sustainability 2021, 23, 5345-5370, doi:10.1007/s10668-020-00819-6.

94. Padalia, H.; Ghosh, S.; Reddy, C.S.; Nandy, S.; Singh, S.; Kumar, A.S. Assessment of historical forest cover loss and fragmentation in Asian elephant ranges in India. Environ. Monit. Assess. 2019, 191, 13, doi:10.1007/s10661-019-7696-5.

95. Sampson, C.; Leimgruber, P.; Tonkyn, D.; Pastorini, J.; Janaka, H.K.; Sotherden, E.; Fernando, P. Effects of illegal grazing and invasive Lantana camara on Asian elephant habitat use. Biological Conservation 2018, 220, 50-59, doi:10.1016/j.biocon.2018.01.021.

96. Jayasankar, C.B.; Surendran, S.; Rajendran, K. Robust signals of future projections of Indian summer monsoon rainfall by IPCC AR5 climate models: Role of seasonal cycle and interannual variability. Geophysical Research Letters 2015, 42, 3513-3520, doi:10.1002/2015g1063659.

97. Lopez-Pujol, J.; Zhang, F.-M.; Ge, S. Plant biodiversity in China: richly varied, endangered, and in need of conservation. Biodiversity and Conservation 2006, 15, 3983-4026, doi:10.1007/s10531-005-3015-2.

98. Acharya, K.P.; Paudel, P.K.; Neupane, P.R.; Kohl, M. Human-wildlife Conflicts in Nepal: Patterns of Human Fatalities and Injuries Caused by Large Mammals. Plos One 2016, 11, doi:10.1371/journal.pone.0161717.

99. Chen, Y.; Marino, J.; Chen, Y.; Tao, Q.; Sullivan, C.D.; Shi, K.; Macdonald, D.W. Predicting Hotspots of Human-Elephant Conflict to Inform Mitigation Strategies in Xishuangbanna, Southwest China. Plos One 2016, 11, doi:10.1371/journal.pone.0162035.

100. Gubbi, S.; Swaminath, M.H.; Poornesha, H.C.; Bhat, R.; Raghunath, R. An elephantine challenge: human-elephant conflict distribution in the largest Asian elephant population, southern India. Biodiversity and Conservation 2014, 23, 633-647, doi:10.1007/s10531-014-0621-x.

101. Jadhav, S.; Barua, M. The Elephant Vanishes: Impact of human-elephant conflict on people's wellbeing. Health $\mathcal{E}$ Place 2012, 18, 1356-1365, doi:10.1016/j.healthplace.2012.06.019.

102. Lamichhane, B.R.; Subedi, N.; Pokheral, C.P.; Dhakal, M.; Acharya, K.P.; Pradhan, N.M.B.; Smith, J.L.D.; Malla, S.; Thakuri, B.S.; Yackulic, C.B. Using interviews and biological sign surveys to infer seasonal use of forested and agricultural portions of a human-dominated landscape by Asian elephants in Nepal. Ethology Ecology E Evolution 2018, 30, 331-347, doi:10.1080/03949370.2017.1405847.

103. Puyravaud, J.-P.; Davidar, P.; Laurance, W.F. Cryptic destruction of India's native forests. Conservation Letters 2010, 3, 390-394, doi:10.1111/j.1755-263X.2010.00141.x.

104. Bai, Z.G.; Dent, D.L.; Olsson, L.; Schaepman, M.E. Proxy global assessment of land degradation. Soil Use and Management 2008, 24, 223-234, doi:10.1111/j.1475-2743.2008.00169.x.

105. Jathanna, D.; Karanth, K.U.; Kumar, N.S.; Karanth, K.K.; Goswami, V.R. Patterns and Determinants of Habitat Occupancy by the Asian Elephant in the Western Ghats of Karnataka, India. Plos One 2015, 10, doi:10.1371/journal.pone.0133233.

106. Madhusudan, M.D. Recovery of wild large herbivores following livestock decline in a tropical Indian wildlife reserve. Journal of Applied Ecology 2004, 41, 858-869, doi:10.1111/j.0021-8901.2004.00950.x.

107. Pollock, L.J.; Thuiller, W.; Jetz, W. Large conservation gains possible for global biodiversity facets. Nature 2017, 546, 141, doi:10.1038/nature22368.

108. Shi, X.; Yin, Q.; Sang, Z.; Zhu, Z.; Jia, Z.; Ma, L. Prediction of potentially suitable areas for the introduction of Magnolia wufengensis under climate change. Ecological Indicators 2021, 127, doi:10.1016/j.ecolind.2021.107762.

109. Liu, L.; Guan, L.; Zhao, H.; Huang, Y.; Mou, Q.; Liu, K.; Chen, T.; Wang, X.; Zhang, Y.; Wei, B.; et al. Modeling habitat suitability of Houttuynia cordata Thunb (Ceercao) using MaxEnt under climate change in China. Ecological Informatics 2021, 63, doi:10.1016/j.ecoinf.2021.101324 